Portland State University

PDXScholar

4-13-1994

\title{
Simultaneous Interpretation (SI): An Information Processing Approach and Its Implications for Practical SI
}

Doris Maria Ecker

Portland State University

Follow this and additional works at: https://pdxscholar.library.pdx.edu/open_access_etds

Part of the Bilingual, Multilingual, and Multicultural Education Commons Let us know how access to this document benefits you.

Recommended Citation

Ecker, Doris Maria, "Simultaneous Interpretation (SI): An Information Processing Approach and Its Implications for Practical SI" (1994). Dissertations and Theses. Paper 4726.

https://doi.org/10.15760/etd.6610

This Thesis is brought to you for free and open access. It has been accepted for inclusion in Dissertations and Theses by an authorized administrator of PDXScholar. Please contact us if we can make this document more accessible: pdxscholar@pdx.edu. 


\section{THESIS APPROVAL}

The abstract and thesis of Doris Maria Ecker for the Master of Arts in TESOL were presented April 13, 1994, and accepted by the thesis committee and the department.

COMMITTEE APPROVALS:

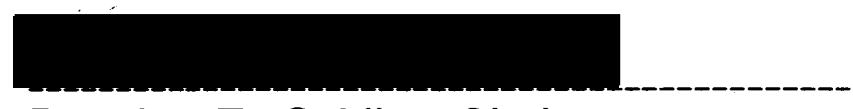

Beatrice T. Oshika, Chair
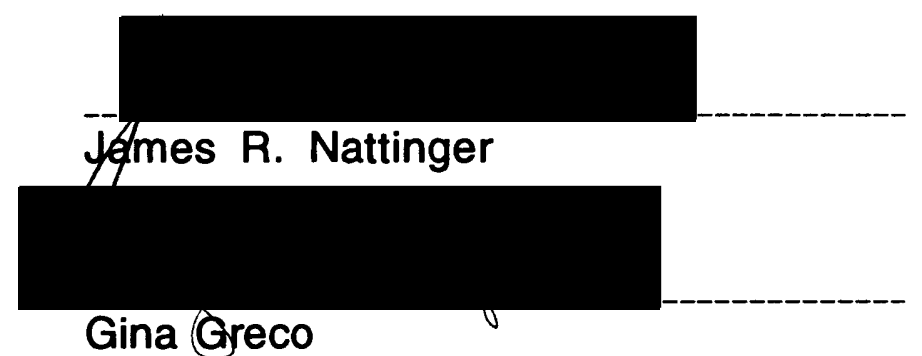

Representative of the Office of Graduate Studies

DEPARTMENT APPROVAL:

Jámles R. Nattinger, Chair

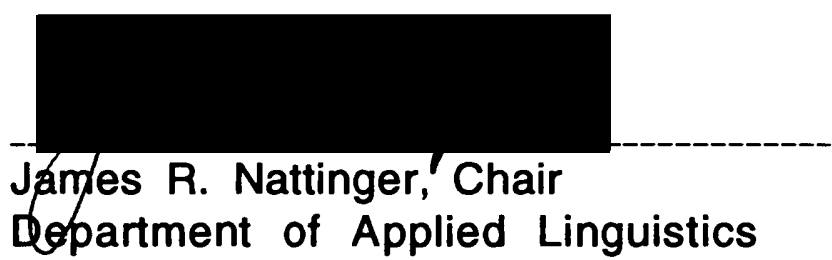

ACCEPTED FOR PORTLAND STATE UNIVERSITY BY THE LIBRARY by on $x+122 y-1924$ 


\section{ABSTRACT}

An abstract of the thesis of Doris Maria Ecker for the Master of Arts in TESOL presented April 13, 1994.

Title: Simultaneous Interpretation (SI): An Information Processing Approach and Its Implications for Practical SI

Simultaneous interpretation $(\mathrm{SI})$ is a special kind of translation where the interpreter listens to a speaker, processes the spoken (or signed) source language message and produces an equivalent output in a target language, i.e., the interpreter produces one part of the message in the target language while simultaneously listening to the next part of the message in the source language. This thesis examines the process of simultaneous interpretation from an information processing point of view and describes the implications of such an approach for practical SI.

Following an overview of research issues in SI literature, a definition of $\mathrm{SI}$ is given, pointing out the special characteristics of SI and the features that distinguish it from written translation and consecutive interpretation. A model incorporating various structural and functional components is then used to describe SI 
in terms of information processing. The focus of this investigation is on the integrative use of bottom-up and top-down processing mechanisms as typical features of human information processing systems. Subsequently the implications of the observations made about $S I$ as an information process are considered within the context of practical SI. The various factors that influence the quality, speed and reliability of interpretation at all stages of the process are examined. Finally suggestions for the training of simultaneous interpreters are made. The thesis is concluded with the observation that $S I$ is indeed a special kind of human information processing. Modelling $S I$ in terms of information processing can contribute to the understanding of this complex process and its components. It is a powerful tool to enlighten the mechanisms and skills involved in SI and to establish efficient training programs for simultaneous interpreters. 
SIMULTANEOUS INTERPRETATION (SI):

AN INFORMATION PROCESSING APPROACH

AND ITS IMPLICATIONS FOR PRACTICAL SI

by
DORIS MARIA ECKER

A thesis submitted in partial fulfillment of the requirements for the degree of

MASTER OF ARTS

in

TESOL

Portland State University

1994 


\section{CHAPTER}

I INTRODUCTION ...................................................................... 1

I I REVIEW OF THE LITERATURE............................................ 6

Early research.................................................................. 6

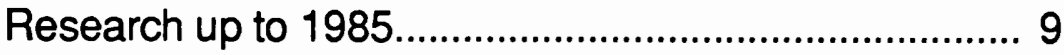

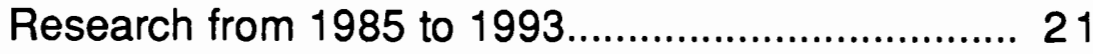

III A DEFINITION OF SIMULTANEOUS INTERPRETATION...................................................................... 40

IV AN INFORMATION PROCESSING APPROACH TO SIMULTANEOUS INTERPRETATION.................................... 50

Characteristics of the information processing approach................................................... 50

The Model..................................................................... 55

Feature Detection

Primary Recognition

Secondary Recognition

The Generated Abstract Memory (GAM) Stage

Synthesis and Output

Auditory Feedback and Output

Correction 
Some Theoretical Considerations.

Attention and Processing Capacity

Memory and Knowledge Representation

Expertise

$V \quad$ IMPLICATIONS OF AN INFORMATION

PROCESSING APPROACH FOR PRACTICAL SI

85

Prerequisites................................................................ 85

SL input and analysis.............................................. 90

$S L$ input rate

Density, redundancy and other idio-

syncracies of the input

Input chunking and initial processing

Syntactic and semantic processing

Synthesis, output and evaluation.

Synthesis and target language output

Evaluation

Training of simultaneous interpreters

VI CONCLUSION 


\section{LIST OF FIGURES}

FIGURE

PAGE

1. An Information Processing Model of Simultaneous Interpretation.......................................................................... 56 


\section{CHAPTER 1}

\section{INTRODUCTION}

Cognitive psychology has for some time now been dominated by the so-called information processing approach, which is minimally characterized by an input or stimulus, a sensory system, a feature analysis system, an input-to-output process via representations of formal symbols and processes, stimulus-driven (i.e., bottom-up) and/or concept-driven (i.e., top-down) processing mechanisms, and an output or response system.

Simultaneous interpretation can be defined as the process during which an interpreter listens to a speaker, processes the spoken source language (SL) message and produces an equivalent output in a target language (TL) simultaneously, i.e., the interpreter speaks one part of the message in the TL while simultaneously listening to the next part of the message in the SL.

Although the process of simultaneous interpretation (SI), with its manifold, concurrent cognitive activities from an input in a source language to the output in a target language, lends itself to an investigation from an information processing perspective, very few attempts have been made so far to capture the complexity of processing in SI from this point of view. 
The purpose of this thesis is the investigation of $\mathrm{SI}$ as a special kind of human information processing and as "the only activity that belies the axiom that the human brain is incapable of performing two complicated tasks at the same time." (Viaggio 1988, 399) Taking place in short-term and long-term memory through devices for decoding a spoken message in a source language and encoding it in a target language via non-language-specific semantic representations, SI can be modelled as a set of complex skills that involve bottom-up or stimulus-driven, and top-down or conceptdriven processes, which are integrated by means of a style of operation that is cascaded and interactive. The focus of the investigation of $\mathrm{SI}$ as a human information process in this thesis will be on just that interaction between bottom-up and top-down processes and on the implications of such an information processing approach for practical SI.

While some books and a considerable number of articles on single practical and theoretical issues in SI have appeared over the years, little comprehensive research has been carried out on the subject as a complete process. Often subsumed under the wider focus of 'translation' or dismissed altogether as a minor form of it, the investigation of $\mathrm{SI}$ as a complex process involving numerous stages and multiple linguistic and cognitive skills has attracted little attention in the research community. Isolated, experimental research and unrelated, individual findings have prevailed, and continue to do so, and have led to a lack of an overall perspective of $\mathrm{SI}$ as a special case of human information processing. 
Simultaneous interpretation embodies all features of information processing, ranging from the input of inherently meaningless, chaotic sensory stimuli, their conversion into discrete units of data, and short-term and long-term memory systems that can process, store, retrieve, and reuse data, to representations that stand for symbols and formal processes, top-down and bottom-up processing mechanisms, a response or output system, and a final output. As it appears to be an ideal candidate for a logical analysis in the form of an information processing model, it is all the more surprising that few efforts have been made to consider SI as a process during which the surface structure of the original source language message is decoded and mapped into some abstract representation, which is then mapped into a new surface structure, and finally articulated as an equivalent target language message. In that context the interaction of knowledge-driven and stimulusdriven processes is of particular relevance and interest, although it is in fact one of the least well-documented aspects in information processing and SI literature. Attempts to specify the mental operations involved in $\mathrm{SI}$ in detail are scarce and date back well over a decade (e.g., Gerver 1976; Moser 1978; Massaro 1978)

Recent research in cognitive science has, to some extent, focused on issues such as memory and knowledge representation that are also important to the SI process and could help to analyze and clarify the skills involved in SI.

As "bilinguality is indeed a prerequisite" (Hamers and Blanc $1989,244)$ for the profession of simultaneous interpreters, 
research in bilinguality can be a source of useful contribution to questions concerning information processing in SI. Although models of information processing in bilinguals may help to gain more insight into the skills and processes underlying SI, most researchers and professional interpreters agree that processing one language for comprehension and another for production simultaneously in a fluent, continuous manner under time constraints and psychological pressure goes far beyond the naturally occurring ability of bilinguals to translate and code-switch. It requires extensive training and experience, but also calls on special cognitive operations and almost perfect linguistic and extra-linguistic fluency in two or more languages.

Although professional interpreters are often not in favour of SI theory as they regard it as useless to the practice of their profession, they can themselves make valuable contributions to research in $\mathrm{SI}$ by investigating methods of training and other practise oriented issues. In return practical SI may profit considerably if comprehensive and detailed answers to the questions of how exactly SI works and which cognitive and linguistic abilities characterize it can be found within the framework of an information processing perspective.

To illuminate "the craft of the human translator as an expert system" (Nirenburg 1987, 10), the form and structure of representations, and different aspects of the processes involved from an information processing point of view will hopefully help to lift "un coin du voile qui recouvre la boîte noire des méchanismes 
cérébraux" (Lederer 1981, 400) [a corner of the veil that covers the black box of mental mechanisms] (my translation). 
CHAPTER ॥

\section{A REVIEW OF THE LITERATURE}

The goal of this review will be to point out the main issues that researchers have tried to investigate over the last four decades, rather than to try and give an exhaustive and detailed account of empirical and theoretical SI research. Since isolated, experimental investigations and unrelated individual findings have prevailed and continue to do so, this will be a chronological review in three parts that summarizes the research of the early days, the 'heyday' of SI research, and the more recent publications. Within each part a thematic order is used to trace the development of interest in SI over the years. The review of $\mathrm{SI}$ literature will be complemented by a very brief overview of selected recent publications on cognitive science and information processing.

\section{EARLY RESERACH}

Although interpretation was part of multilateral communication even in ancient cultures such as Egypt and Rome (Kurz 1986a, 1986b), the profession of simultaneous interpreting in our modern culture only gained official status with the Nuremberg Trials in 1945/46. The initial notion of interpretation as a word- 
for-word transliteration prevailed for a considerable time, and it was not until 1957 that the first analysis of simultaneous interpretation appeared in the form of a Master's thesis. Paneth (1957) focused her discussion on the training of simultaneous interpreters, but also introduced the issues of input segmentation and the interpreter's use of speaker pauses to accelerate the TL output. She observed a time-lag of two to four seconds between the speaker and the interpreter output, as well as the ability of some experienced interpreters to carry out tasks like knitting or writing letters while interpreting.

The first experimental studies involving simultaneous interpretation were carried out by Treisman (1965) and Oleron and Nanpon (1965) on the effect of redundancy of the SL message on earvoice $\operatorname{span}^{1}$ (EVS) and the accuracy of performance, and on the variation of EVS according to the length of passages translated into different languages respectively. Treisman observed that redundancy actually had an effect on the number of words interpreted correctly and described the greater EVS for interpreting (in comparison to shadowing) to be a consequence of complex transformations between input and output. Oleron and Nanpon found that the observed EVS two to ten seconds is a function of the relative difficulty the interpreter encounters in organizing the input material.

${ }^{1}$ The ear-voice span in the given context is "the time between the moment a message unit reaches the ear and the moment it is reproduced in the target language" (Hamers and Blanc 1989, 248) 
Lawson's (1967) investigation of selective attention for verbal input did not focus on SI, but was indirectly related to the observation of different tasks carried out concurrently made by Paneth (1957). Lawson found the interference from non-attended channels to be dependent on the type of auditory interference.

Similarly, Goldman-Eisler (1967) investigated the role of patterns of speaking and pausing in SI, spontaneous speech, and reading. He suggested that "cycles of acts of planning and production in speech" (Gerver 1976, 171) are reflective of the alternation between periods of short speech bursts and long pauses and periods of short pauses and long speech units that he observed for reading, spontaneous speech, and SI. The presumption that these cycles could reflect a rhythm of cognitive activity was partially refuted by a demonstration carried out by Schwartz and Jaffe (1968), in which they showed that the same stepwise patterns observed in natural speech by Goldman-Eisler occurred in computer-generated random sequences of speech.

The only publication to appear in book form in the early days of SI research is Seleskovitch's L'Interprète dans les Conférences Internationales (1968). Based on fifteen years of SI practise and teaching experience, Seleskovitch's attempt to trace the techniques used in simultaneous and consecutive interpretation was one of the first to define the methods and conditions that allow successful interpreting from a semantic point of view. The focus of her work was the evocation of a semantic field and the extraction of sense from the linguistic framework of words. She decomposed the 
process of interpreting into three parts: the perception of a linguistic unit charged with 'sense', i.e., the apprehension and comprehension of a message via analysis and exegesis; the immediate forgetting of the signifier, while a mental image of the signifie is retained; and finally the production of a new signifier in the target language. The identification of meaning is a typical feature of Seleskovitch's early approach to SI and was in the future to be developed into what became known as the "SeleskovitchLederer paradigm" (Mackintosh 1985, 37), which to this day constitutes the basis for research and teaching at the Ecole Superieure des Interpretes et Traducteurs (ESIT) in Paris, one of the most prestigious universities in the domain of interpretation and translation.

\section{RESEARCH UP TO 1985}

The fifteen years that followed the days of 'early' research can be considered to have been the heyday of SI theoretical and applied research. This lively interest found its expression in the publication of one of the very few comprehensive books on SI. Language. Interpretation and Communication (Gerver and Sinaiko 1978). This is a much quoted collection of papers, some of which are reviewed in more detail below. In this book gerver and Sinaiko attempted to bring together research in behavioral sciences and professional interpretation. It contains contributions from leading researchers and professional interpreters, covering a variety of topics ranging 
from models of processing (e.g., Moser 1978, Massaro 1978) and bilingualism (e.g., Lambert 1978) to artificial intelligence (Wilks 1978) and the interpretation of sign language.

As one of the common features of language behavior is turntaking, i.e., the consecutive alternation between listening and speaking, the rather exceptional phenomenon of simultaneous speaking and listening that characterizes SI, evoked great interest in the research community. One step towards an explanation of this phenomenon was taken through the investigation of SL segmentation, $S L$ input rate and the role of speaker pauses.

In an attempt to test Barik's (1969) suggestion that SL pauses delineate units-to-be-encoded by the interpreter, Goldman-Eisler (1972) analyzed experienced interpreters and identified three types of chunking that seemed to demonstrate that interpreters have their own ways of input segmentation: (1) identity, i.e., the interpreter awaits a speaker pause in order to encode a complete chunk in the target language; (2) fission, i.e., starting the encoding of a chunk before the end of the SL production; (3) fusion of two or more SL chunks into a single output unit.

Based on the ear-voice span, Goldman-Eisler (1972) identified seven categories which fit the assumed EVS length of four to five words: (1) adverbial expressions and NP (noun phrase) only; (2) NP+VP (verbal phrase) without object; (3) NP+VP with object, adverb, etc.; (4) NP +VP plus part of the following clause; (5) clause continued, i.e., middle of clauses; (6) end of clauses; (7) end of clauses plus part of the next clause. The majority of EVS units were 
found to consist of at least one complete predicate expression. Goldman-Eisler concluded from his study that the crucial unit of meaning for the interpreter is predicative rather than lexical, and that interpreters use their own strategies of input chunking rather than the structure imposed by speaker pauses.

Barik (1973) demonstrated that interpreters do make greater use of speaker pauses than one would expect assuming that the interpreter's output is independent of alternating speaking and pausing in the $S L$ delivery. He inferred that the pauses are used by the interpreter to reduce the time spent speaking and listening simultaneously. As Stenzl (1983) pointed out, there have been no attempts to correlate these findings to the quality of the interpreter's performance. She concluded that pauses force the interpreter to constantly adjust his output pace to the speaker's rhythm and therefore complicate rather than facilitate the task.

Considering that ninety-six percent of the SL pauses were found to be shorter than two seconds, forty-eight percent were as short as 0.25 and 0.5 (Gerver 1972b), and that the average SL articulation rate ranges from ninety-five to one hundred and twenty words per minute Gerver (1972b) concluded that it seems highly unlikely that the interpreter could cram enough output into these short pauses in an attempt to minimize the time of simultaneous listening and speaking. He observed the latter to lie between sixtyfour and seventy-five percent.

Seleskovitch (1968) and Gerver (1969) both found an SL input rate between ninety-five and one hundred and twenty words per 
minute to be optimal for simultaneous interpretation. They considered a very slow as well as a very fast SL delivery to be most stressful for the interpreter and likely to affect the quality of performance.

Chernov (1969) suggested that compression of the SL text can help the interpreter to cope with too high an input rate, while Miller (1964) observed the following strategies to be employed by the interpreter under the same circumstances: (1) omission (not processing the information overload); (2) escape (cutting off the input); (3) error (incorrect processing or failure to correct output); (4) queueing (delay response and try to catch up during periods of slower input); (5) filtering (systematic omission); (6) approximation (less precise reconstruction of SL input).

Interest was also drawn to the question of whether, and if so to what extent, listening and speaking simultaneously affect performance on cognitive tasks. In an experiment involving tests of comprehension and recall after listening to, shadowing and simultaneous interpreting French prose passages, Gerver (1974) observed that test scores were higher after listening than after shadowing or interpreting. Also, scores were significantly higher after interpretation than after shadowing. He concluded that, although simultaneously listening and speaking impairs comprehension more than simply listening, the impairment is higher when a monolingual repetition of the message is involved.

The findings of a similar study by Lambert (1983), who included consecutive interpretation in her tests, coincided with 
Gerver's observations. His and Lambert's findings, together with the results of a study conducted by Pintner (1969), in which he demonstrated that simultaneous interpreters can carry out complex cognitive tasks while simultaneously listening and speaking, suggested that while the simultaneity of listening and speaking itself does not prevent the performance of concurrent cognitive tasks, it can restrict the efficiency and quality of performance in SI.

Other listening conditions that can have an effect on the interpreter's performance were investigated by Gerver $(1972 a, 1974)$. In a study on the effects of noise, he observed that with increasing noise the number of omissions and errors rose, while the EVS remained fairly constant. Gerver suggested that even under bad listening conditions, interpreters try to keep the EVS constant at the expense of lower response criteria, a higher rate of errors and less attempts to correct their own output.

In the same context Pinhas (1972) discussed the question of whether it is better to interpret into or from one's mother tongue, especially under poor listening conditions. In his opinion interpreters should translate into their mother tongue only under good listening conditions (i.e., when the SL input allows easy decoding) even if the knowledge of the $S L$ is not one hundred percent native speaker-like. However, he recommended interpretation from the mother tongue under difficult listening conditions, when a perfect grasp of the SL language is necessary to decode the input effectively and correctly. 
$\mathrm{SI}$ as well as shadowing, a task to which $\mathrm{SI}$ is often compared, demand that attention is divided between two sources: the speaker output (i.e., the input for the interpreter) and the output generated by the interpreter. Neisser's (1966) suggested that the corresponding parallel processing takes place at a pre-attentive level at which information that can not be processed immediately is either rejected or stored for later use. He indicated that responses that are processed at this pre-attentive level have probably become automatisms.

Having observed that experienced interpreters were better than untrained bilinguals at answering cognitively demanding questions Pintner (1969) concluded that interpreters learn how to automatize part of their simultaneous processing and therefore are able to pay more attention to other cognitive tasks.

Welford (1968) attributed the facility with which experienced simultaneous interpreters listen and speak simultaneously to their ability to ignore the feedback from their own voices. This presumption is based on the phenomenon that simultaneous interpreters often claim to have little conscious knowledge of what they have said while interpreting.

The findings of Welford are called into question by the fact that interpreters often correct their own output. Gerver (1974) suggested a monitoring procedure carrying out self-correction similar to that of the TOTE (test-operate-test-exit) mechanism introduced by Miller, Gallanter and Pribram (1960). According to them, a target language response that has been generated and 
uttered is tested again. The interpreter proceeds to the next item if the second test is passed. Otherwise the interpreter 'operates' again, generating a new response to the same stimulus.

Gerver (1976) investigated the question of output control further and developed a model based on the assumption that the $S L$ message can be stored in some form long enough to be compared to the translation. He described the mechanism involved as a loop that allows the interpreter to check the generated TL message by decoding it and subsequently matching the derived meaning with that of the original message. In case of a mismatch, the interpreter can either correct, stop, or prevent his output and retry, i.e., loop through the routine again. Whether and how extensively that mechanism is used depends, according to Gerver, on the interpreter's performance criteria.

Gerver's hypothesis was supported by an experiment conducted by Treisman (1964), who suggested that secondary channel information (i.e., the interpreter's own output) is attenuated and analyzed together with the original SL message via a series of hierarchical tests based on simple statistical decisions.

Gerver (1976) also considered the possibility of the output control being an integral part of simultaneous interpretation rather than an additional process occurring subsequently to translating. This idea was based on an analysis-by-synthesis approach that incorporates a hypothesis-generating process of translation (continuous generation, monitoring, and testing of the translation against the $S L$ message) and an analysis involving the internal 
synthesis of a unit of meaning against which the unit under analysis is matched.

The role of memory in SI was discussed as early as 1962 by Van Hoof, who assumed a split of memory and attention in view of the numerous tasks that the interpreter has to carry out simultaneously.

Hromosova (1972) described memory as a three-track system, where storage begins as soon as the SL input starts. At the same time lexical and grammatical knowledge of SL and TL are brought in and the cycle continues as the translation is pronounced.

Massaro (1978) distinguished three kinds of short-term memory (Perceptual Auditory Storage; Synthesized Auditory Memory; Generated Abstract Memory) that interact with long-term memory. He assumed that the latter is "a multidimensional representation with both perceptual and conceptual attributes" (Massaro 1978, 311) and that "language understanding involves going from perceptual codes to conceptual ones, whereas production goes in the reverse direction." (ibid.)

Moser (1978) also pointed out the multilevel character of short-term memory and emphasized its constant interaction with long-term memory, where SL and TL equivalents are stored within the same concept.

Seleskovitch (1976) distinguished formal from semantic memory. The former is responsible for the acquisition, storage and recall capacity of acoustic shapes and their associated mental patterns (therefore referred to as the memory of language). 
Semantic memory refers to the memory of non-verbal knowledge and is related to the ability to remember meanings in the form of concepts.

Lederer (1981) postulated the mobilization of the contents of a cognitive memory by sounds. She described a so-called immediate memory that conserves seven to eight words for a very short moment (approximately two to three seconds) during which sound and signification are associated with each other. In addition, a cognitive memory in which form is dissociated from content enables the interpreter to retain cognitive traces.

Research in the long-term memory (LTM) organization of bilinguals may shed some light on how LTM is organized in simultaneous interpreters. The controversy whether the commonstorage hypothesis or the separate-storage hypothesis offers the right model for the bilingual's memory has not been resolved yet.

Basing his opinion on empirical evidence McCormack (1977) argued in favour of the former, in which a switch between the two language systems is assumed to be situated before a common semantic memory.

Kolers (1973), on the other hand, supported the separatestorage model according to which the switch between the two languages occurs at a much deeper level and each language has its own lexicon and memory devices.

There has also been some research regarding the linguistic skills and bilingual competence involved in SI, since highly developed language skills in one or two active and several passive 
languages as well as verbal and cognitive skills are generally regarded as prerequisites for the profession of simultaneous interpreters.

Carroll (1978) found cognitive factors, a verbal intelligence factor, and a general cultural factor as well as the following fluency factors to be relevant to interpretation and translation: (1) word fluency that enables the interpreter to manipulate orthographic units such as prefixes; (2) ideational fluency to facilitate the evocation of ideas; (3) expressional fluency for the rapid retrieval of appropriate lexical expression of ideas; (4) associational fluency which facilitates the right lexical items from a restricted semantic field. According to Carroll verbal fluency is unrelated to these factors, while there is a connection between the latter ones and the facility of competently storing, retrieving and manipulating units of information.

Although there is a consensus on the fact that $\mathrm{SI}$ requires a certain level of bilinguality, no agreement has yet been reached as to what type of bilingualism might be the most appropriate. Harris and Sherwood (1978) suggested that infant bilinguals make good translators and interpreters, because they show the ability to translate from one language into another while retaining the meaning of the message at a very early stage. Andersen (1976) argued that coordinate bilinguals are best equipped for the task of SI, as they have a separate cognitive unit for each translation equivalent. On the other hand, studies in information processing in bilinguals (Genesee, Hamers, Lambert, Mononen, Seitz, and Starck 
1978) demonstrated a preference of early bilinguals for semantic processing, and of late bilinguals for phonetic processing. This suggests a possible advantage of early bilinguals for the performance of cognitive tasks involved in SI.

While in the last decade of research in SI only one attempt was made to model the process of interpretation, several models have been proposed during the heydays of SI.

The earliest attempt appears to be Massaro's (1978) information-processing model of understanding speech. His model comprised feature detection, primary recognition, secondary recognition, rehearsal and recoding as functional components and their corresponding structural components. Massaro described the information flow starting with the transformation of mechanical into neural information. The subsequent evaluation of acoustic features in the Perceptual Auditory Storage and their match against those that define perceptual units in long-term memory is followed by the syllable-by-syllable transformation of synthesized percepts into meaningful forms during secondary recognition in Generated Abstract Memory. Rehearsal and recoding form the final stage in this model. Massaro's model focuses on semantic operations following the loss of the verbal character of the information. These operations involve a memory search of the conceptual base and the subsequent activation of conceptual relations. Massaro also considered the question of the organization and access of language-independent semantic and language-dependent syntactic information and addressed memory as a multi-level component. 
Moser (1978) based her model on Massaro's. She attempted "to describe the activities involved in understanding and production." (Moser 1978, 353) According to her, sound patterns that reach the ear are received by a passive auditory perception system and are stored in a Perceptual Auditory Storage. They subsequently undergo primary recognition according to the phonological rules of the SL. The emerging synthesized percepts (syllables) are stored in Synthesized Auditory Memory as a string of perceptual units. Finally the process of secondary recognition, which depends on syntactic and semantic cues, preceding context and lexical stress patterns, transforms them into words and word strings. At the subsequent Generated Abstract Memory stage the information segments are further processed on a semantic-conceptual level where semantic organization takes the form of a language-independent conceptual base. Moser described the latter as consisting of concepts and relations between them. During understanding, the linguistic structures of the SL are mapped onto this basis, which stores $S L$ and TL equivalents within the same concept. Once inter-and intralingual conceptual relations are activated the TL message can be generated according to specific syntactic rules of the language in question. Moser also addressed the question of semantic and syntactic organization in detail and discussed the influence of prediction, context and knowledge, and the way in which interpreters deal with their own feedback. She emphasized the interaction of long-term memory with ongoing processing at almost all levels and integrated several rehearsal-loops at decision points into her model. These 
allow the interpreter to revise, correct, and trace back prior decisions of the process.

Gerver (1976) incorporated a model of the SI process based on a simple information-processing approach with a focus on memory and attention in his work. He suggested the involvement of a shortterm buffer memory, a relatively short-term memory, a short-term output buffer memory and a "long-term storage of the lexicons and grammars of both source and target languages, interacting with the other processes involved with the reception, transformation and production of language." (Gerver 1976, 191)

The two main aspects of his model are the permanent structural features and the control processes that the interpreter can select to determine the distribution of attention to different task components.

\section{RESEARCH FROM 1985 TO 1993}

Considering the few publications on $S I$ in the last decade, it seems that the interest in simultaneous interpretation has declined considerably. This is in surprising conflict with the fact that $\mathrm{SI}$ as a means of international and multilingual communication continues to gain importance in all sectors of human interaction.

The research in $\mathrm{SI}$ tends to be published in form of single articles in magazines such as Meta and Babel. The absence of a common focus or a unifying link between these publications is, more so today than in the early days of SI research, a problem that makes 
it hard to extract trends or major issues in contemporary SI research.

An appreciable exception to the body of unrelated, individual articles is Chapter 10 in Hamers and Blanc's Bilinguality and Bilinqualism (1989). It is dedicated to "interpretation, translation and bilinguality" (Hamers and Blanc 1989, 244-254) and focuses on simultaneous and consecutive interpretation. Questions concerning simultaneous speaking, listening and processing, the role of speaker pauses, input chunking, the interpreter's linguistic skills, and bilingual competence are considered along with related issues such as memory, attention, and the modelling of information and text processing. In addition to being an excellent source of reference, the chapter also provides further suggestions for topics of investigation, such as the interpreter's personality and the relevance of interpretation studies for artificial intelligence and computer translation and vice versa.

To celebrate its thirtieth anniversary (1985) the journal Meta brought out a special issue on conference interpretation. It contains a wide range of articles (some of which are considered in more detail in this review) on topics ranging from the investigation of interpretation as a multi-channel communication phenomenon and the role of interpreters in the Nuremberg Trials to the conference interpreter's working environment and the understanding of the ease of anticipation in verb-final languages.

Bell's recently published Iranslation and Translating (1993) deals with the written form of translation rather than with 
interpretation, but offers interesting insights into issues that are relevant to interpretation. Focusing on translation as a process, various perspectives on translation are introduced, incorporating questions concerning equivalence, methodology, the use and relevance of theories, models, and analogies. Considering the modelling of the translation process, Bell investigated the notions of knowledge, skills, and expertise as well as possible components and processes including synthesis and analysis. Of special interest are the chapters subsumed under "Memory" (Bell 1993, 199-226), including questions of text processing and an investigation of human information-processing, knowledge representation, and memory systems, which can all be applied, to a certain degree, to SI.

DeBot's (1992) adaptation of the so-called speaking model (Levelt 1989) focused on production, but due to its investigation of conceptualization and feedback mechanisms, automatization, incremental and parallel processing, is a useful contribution to SI research. Among the phenomena that are typical for interpretation and bilingual speech and have to be accounted for by a model, DeBot pointed out the possibility of separate or mixed use of two or more language systems, cross-linguistic influences, and the absence of deceleration of production with additional languages. In addition to that he found different degrees of mastery, and the potentially unlimited number of languages and their interaction in the multilingual brain to be salient issues in bilingualism and interpretation. He assumed a combination of a large storing system with a mechanism that allows the separation of the languages 
involved, a non-language specific knowledge component, a language specific conceptualizer, and a mental lexicon with language specific lemmas as the crucial link between meaning and syntax.

Although Gile (1989) states that "il ne s'agit plus de devoiler le mystère de la «simultanéité>>" (Gile 1989, 649) [the issue is no longer to unveil the mystery of simultaneity] (my translation), the issues of simultaneity and attention have recently been investigated anew under the aspect of processing capacity. Gile $(1985,1991)$ introduced a so-called effort model (medèle d'efforts) that comprises the following three distinct sets of operations or efforts in the interpretation process: (1) the effort of listening to and analyzing the source language speech; (2) the effort of producing a TL speech; (3) the effort of STM storage and information retrieval for strategic or linguistic reasons. Depending on the task that has to be tackled at any one moment each of these efforts has a particular processing capacity requirement. As attention and overall processing capacity are variable but limited, the sum of all efforts may not be equal to or exceed the maximally available capacity, if successful and complete processing shall be maintained. Gile also discussed the possibilities of a breakdown due to inappropriate effort distribution. He claimed that this effort model can explain interpretation problems (translation of enumerations, names, foreign accents, and grammatically incorrect or syntactically difficult input) as well as the facilitating influence of anticipation on the interpretation process. According to Gile overall processing capacity, strategies to manage (i.e., allocate and shift) effort 
requirements appropriately, and to compensate for an overload in any of the sets of operations are subject to development through training.

The relevance of the proposed model for simultaneous as well as consecutive interpretation seems to be confirmed by an experiment on note-taking and attention conducted by Gile (1991b). He found that note-taking while interpreting "constitue une menace pour la qualite de l'ecoute" (Gile 1991b, 434) [constitutes a menace to the quality of listening] (my translation) as it focuses attention on writing efforts at the expense of listening and understanding. He also confirmed the long-standing assumption that note-taking supports memory and therefore reduces efforts to reconstruct the message in the target language. In order to reduce processing capacity and time-requirements for note-taking, while maintaining the efficiency of notes as a memory reinforcement, the interpreter is advised to use symbols and abbreviations in note-taking and to take notes in the source language.

Gile $(1985,1989)$ also tackled the question of attention in a more applied consideration of attention management in listening to a SL speech of a highly technical nature. He claimed that dense technical and quantitatively important information does not leave the interpreter the time necessary to retrieve all phrases, concepts, and arguments of the input. According to him only excellent domain knowledge, thorough conference preparation and a well-developed training programme can help to overcome the difficulties arising from the complex and attention-demanding tasks involved in SI. 
Gile aiso put SI into a sociological and communicative context, considering the main types of interlinguistic conferences (e.g., scientific and technical conferences, seminaries and technical courses, international negotiations, radio debates, press conferences) that provide a possible framework of working conditions for the interpreter. He classifyed them according to density of information presented, specialization of vocabulary, cognitive differences between speakers and listeners, number of participants, novelty of the material presented, degree of controversy, availability of documentation on the contents, and nature of the conference in question. In addition to that Gile raised organizational issues of $\mathrm{SI}$ including the importance of the chronological order, acoustic conditions, and lighting and air conditioning. All of them have an important impact on the performance of the interpreter and have often been neglected in favour of linguistic, cognitive, and educational considerations.

Two articles that appeared in 1989 dealt with the training of simultaneous interpreters. Lambert (1989) considered a variety of exercises that put into practise theories derived from findings in cognitive psychology and neurology. She drew on theoretical knowledge as well as personal experience as an instructor of $\mathrm{SI}$ in Europe and Canada and proposed a wide range of exercises that correspond to various cognitive objectives set within a framework of practical SI. Lambert finally suggested that the students try to assess their personal, optimal listening conditions by finding out 
which is their 'preferred' ear for listening and whether they want to hear their own output or not.

Gerver, Longley, Long, and Lambert (1989) based their paper on selection tests for trainee conference interpreters on an empirical study in which future SI students took part in a selection procedure conducted in French and English. The tests that were part of the procedure comprised (1) text-based tests (recall tests, cloze tests, error detection) to test memory, general linguistic performance, and the quick and accurate perception of linguistic details; (2) subskill-based tests (synonym tests, rewriting tests, extended range vocabulary tests) that are supposed to reflect associational and expressional fluency and verbal comprehension; (3) speed stressbased tests (Nufferno test)2; (4) final oral examinations involving simultaneous and consecutive interpretation. The research group provided a detailed account of and comments on statistical results and correlations and concluded that good performance on the first three sets of tests could be associated with a good showing in final interpretation examination. They also found linguistic and nonlinguistic abilities required by interpreters to be reflected by the tests. Furthermore, the researchers claimed that many of the tests which had been found to be significant for the evaluation of interpreting skills were also significantly related among themselves, suggesting that some abilities required by interpreters are reflected by more than one test. Not all tests (e.g., memory

2 test to assess the effect of stress on a cognitive, non-linguistic task 
tests) were equally significantly related to $\mathrm{SI}$ and $\mathrm{Cl}$ examination ratings, a fact that the research group related to the more salient function of reconstructive memory processes for $\mathrm{Cl}$ than for SI. While the tests appear to have been successful in reflecting the abilities required for interpreting, the proposition that they also reflect the subsets of abilities specific to $\mathrm{SI}$ and $\mathrm{Cl}$ still needs to be confirmed.

In a study related to the research of Gerver $(1971,1976)$, Barik (1973) and Goldman-Eisler (1972) on input segmentation, Isham and Lane (1993) conducted a study that investigated the recall of SL sentences in simultaneous interpretation and its relation to the use of sentence boundaries for input processing. They compared verbatim recall of 'normal' listeners to that of interpreters (interpreting a text into American Sign Language, $A S L$ ) and transliterators (producing ASL signs corresponding to English words in English word order, forcing subjects to re-code individual lexical items). While in all three groups the translational probabilities of recalling adjacent words were influenced by syntactic boundaries, primacy and recency effects for the first and the last word of sentences were observed in listeners and interpreters only. Furthermore Isham and Lane noticed that verbatim recall seems to be sensitive to processing goals and demands of the three groups: (1) comprehension and the grouping of input segments into propositions that are said to coincide with the completion of a sentence for listening; (2) sequential production of manual gestures and memory for lexical forms, clauses and word order in transliteration; 
retrieval of representational propositions and grouping into units of processing in interpretation. The outcome of the experiment is summed up by the observation that "interpreters, like listeners, process sentences to represent their propositions, rather than to represent the form of the sentences themselves." (Isham and Lane 1993, 241) The fact that the performance of interpreters resembles that of listeners and not of transliterators suggests that modality can not be the sole reason of differences in processing. As psycholinguistic research points towards different ways of processing for signed and spoken language only at lower-level perceptual stages Isham and Lang suggested that the results they obtained should be similar if the experiment was repeated with pairs of oral languages.

In her article "Discourse processing and interpreting strategies" (1992) Kalina compared the monolingual communication situation to bilingual interpretation. She described the former (consisting of strategic discourse comprehension and text production) as involving a bottom-up understanding of short-lived input that is forgotten when the process is activated, and top-down understanding based on special and general knowledge. In interpretation, where the TL text is a reproduction of the $S L$ message, special strategies have to be present to overcome the constraints imposed by a prolonged presence of bottom-up indicators and the lack of liberty to chose the way of reaction to a perceived utterance. Kalina suggested the following strategies that are derived from the observation of 'think-aloud' utterances of 
interpreters: a highly developed and very reliable anticipation that allows the base production of input on an anticipated hypothesis; top-down monitoring strategies that check anticipated hypotheses and own output at all stages of the process; approximation strategies that involve the accumulation of information to activate and add a more suitable term or phrase; the avoidance of interferences and syntactic reconstruction of the $S L$ text due to a more or less conscious decision to find a better target style. Kalina emphasized that these special strategies can be taught and improved by general exercises involving discourse processing in adverse conditions, anticipation tasks that increase the awareness of bottom-up and top-down processes and unilingual tasks with bilingual conditions artificially built in to improve the ability to cope with SL signposts.

Semantic and pragmatic considerations within the framework of linguistic theory and simultaneous interpretation are the focus of an article by Schweda-Nicholson (1992). Agreeing with Jackendoff (1972) and Lyons (1981) that every major constituent in a sentence corresponds to a conceptual constituent Schweda-Nicholson applied Jackendoff's preference rules to SI. She assumed that out of a group of logically possible decisions which can be made during analysis the interpreter checks converging incoming information against an internal standard dictated by the semantic and syntactic patterns of the source language. This mechanism is simultaneously applied to a small portion of the input structure in a decontextualized situation and to entire structures across small portions. Possibilities 
permitted by the local preference rules can be ruled out. SchwedaNicholson stressed the importance of an adequate time-lag that allows the analysis and constant disambiguation of units of meaning and the consideration of context. She also assumed preference rules to have a default value that allows the interpreter to hypothesize about the whole message in case of an incomplete or degenerated input. She emphasized the use of syntactic and semantic constraints as an additional application of preference rules, implying the possibility to make hypotheses about a sentence while it is processed and to establish meaning and resolve ambiguities subsequently by using semantic and syntactic cues. Assuming that these mechanisms work more effortlessly in one's native or dominant language, Schweda-Nicholson (1992) argued in favour of translation into the interpreter's native or dominant language. Her suggestions for further research included an in depth analysis of language processing strategies in SI, an investigation of $S L / T L$ inferences and additional neurophysiological research.

The lack of a detailed comprehensive study of creativity in interpretation inspired Alexieva (1990) to consider the role of creativity in simultaneous interpretation. Her basic assumption was that, although the generation of the TL output is predetermined by the source language input, there exists no one-to-one correspondence between $\mathrm{SL}$ and $\mathrm{TL}$ units, and that therefore interpreting is not a merely reproductive, but a productive and creative process of decision making. Alexieva emphasized that in interpretation the analysis of a unit (word, phrase, or utterance) can 
be based only on preceding context, knowledge of the overall situation, and predictions of what units are to follow, whereas the translator of written texts can also rely on the larger context of a written text. For the reconstruction of a message the interpreter can choose among a wide range of possible combinations of stylistic, pragmatic, semantic and even syntactic choices, using knowledge, intuition, and creativity in combining them. The number of choices, and therefore the possibility of using creativity, is even increased by the severe time restrictions in SI that often make it necessary for the interpreter to render the TL message in a more concise way, weighing the meaning and style of the SL input against the degree of compression, possible loss, and the quality of the output. Alexieva interpreted this increase of possible alternatives for selection as a decrease of chances for preliminary determined, rule-governed decisions.

Among publications that deal with neurolinguistic aspects of translation and interpretation is an article by Paradis, Goldblum, and Abidi (1989), demonstrating that translation and interpretation are different from understanding and speaking two or more languages. The research group observed the phenomenon of alternate antagonism with paradoxical translation behavior in the speech of two bilingual aphasics which is characterized by two remarkable features:

. . the alternate availability for productive use of one language accompanied by simultaneous lack of access to the other for given periods of time ... [ [and] ... the 
paradoxical ability to translate into a language in which they could not find words for spontaneous use while being unable to translate toward the language in which the words were available for spontaneous use. (Paradis, Goldblum, and Abidi 1989, 67)

Such behavior seems to provide support for the hypothesis that the unrecovered language is not lost but inhibited. In the authors' opinion, the observed behavior excludes the possibility that a direct link between the translation equivalents in the absence of a link from the concept or meaning to the phonological representation of the term is the cause of their ability to translate into a language for which words were not available for spontaneous speech. They concluded a functional independence of two or more languages in one brain and the possibility of a restrictive inaccessibility of the underlying competence of one of the linguistic systems, while performance is differentially or totally inhibited.

Within the framework of neurolinguistic considerations Paradis's (1985) article on the representation of two languages in one brain provided insight into the neurolinguistic realities underlying bilingual processing in general and simultaneous interpretation in particular. According to Paradis bilinguals possess two interactive linguistic systems that are supported by functionally separate neural systems. Language skills and other cognitive skills are believed to be represented as an interactive modular system composed of peripheral sensory and kinesthetic modules for each linguistic skill, a grammar underlying 
understanding, speaking, reading, and writing for each language, and an experimental and conceptual cognitive system that is common for all languages involved but differentially organized by each (Paradis 1985). Among the conclusions he drew the following are of special significance for SI: (1) the functional independence of two or more languages in one brain; (2) a dissociation in performance between comprehension and production; (3) the distinction of languagedependent lexical meanings from language-independent experimental and conceptual mental representations; (4) the storage of words as connected sets of different kinds of representations.

Darò (1992) reviewed a number of neurolinguistic studies using tasks such as tapping or shadowing in their experiments. She assumed the existence of four autonomous, neuro-functional systems in the brains of interpreters: one for the mother tongue (L1) and one for the second language (L2) with separate components for understanding and production in each of them, one for translating from $L 1$ into $L 2$ and one for translating from $L 2$ into $L 1$. Her observation that both hemispheres of the brain are activated according to competence is consistent with theoretical and practical knowledge in SI didactics. However, she suggested that it might be necessary to test this knowledge within a scientific and interdisciplinary framework.

Finally three theoretical philosophical contributions to translation and interpretation will be considered. In an article on interpretation as the elementary manifestation of translation Lederer (1985) postulated the anteriority of oral speech as a 
historical fact, as writing only provides a graphic way of expressing speech. She also emphasized that traces of orality can be found in every written form of speech, because not phrases and sentences, but their cognitive content are remembered, just as is the case in spoken language. In Lederer's opinion the same intellectual and psychological processes are the basis of comprehension in translation and interpretation. The objects of comprehension (ideas, notional and emotional contents of text, and discourse) are the same for both tasks too. Lederer also stressed the difference of the products of the two related tasks, describing translated texts as autonomous, durable, precise, and rich in vocabulary, available to a large, ill-defined public, and interpretation as spontaneous and evanescent and therefore more appropriate to reveal the underlying processes.

The article "L'oralité de la traduction orale" by Garcia-Landa (1985) also stressed the importance of interpretation. Garcia-Landa described oral translation as the most obvious form of communication when it comes to demonstrating that mental spaces (espaces mentaux) are the most important phenomenon of language. In her opinion linguistic structures in spoken language and interpretation represent a primary semiotic transaction that is more affective, more physical, and more evanescent than in the written mode, where the translator "reste prisonnier des chaînes de signes trop présentes et pesantes sur le papier." (Garcia-Landa 1985,31 ) [remains the prisoner of chains of signs that become all too burdensome in writing] (my translation) According to Garcia- 
Landa mental spaces are the outcome of the construction of a mental representation similar to that which the speaker intended to communicate. The sense of what has been said comes into existence when formal and mental spaces are joined to form an undissolvable whole.

The role of theory in simultaneous interpretation has been considered in an article by Poechhacker (1992). She argued that, although theory is often regarded as irrelevant for practical SI and the 'just do it' view prevails, theory is an important prerequisite for the teaching of SI. Reviewing several theories she proposed a general theory of translation and interpretation (GTI) that describes SI as the act of target text production in synchronization with the production and/or presentation of a source text. This act is supposed to take place within the framework of a network of interaction between the initiator, client, speaker, source text listener, interpreter, and target text listener or user. Her focus being the communication situation that underlies SI, Poechhacker suggested the study of on-line processing and associated cognitive operations and of the conference as a hypertext. She described this hypertext as a communication situation for a special purpose, with the author's intentions, the intended audience, the topic, the text type, and the discourse structure as parts of a comprehensive theory of SI.

Only one model for the process of interpretation has been proposed in recent years: Mackintosh's (1985) application of the Kintsch and VanDijk (1978) model of comprehension and production. Mackintosh's semantic processing model referred mainly to 
consecutive interpretation but is also relevant for SI. It involves the organization of the text into a coherent whole, the condensation of its full meaning into its gist and the generation of a new text from memory traces. The surface structure of the original message is described as a set of micro propositions (present in the surface structure or derived from prior knowledge) to which macro rules are applied that transfer the micro structures into macro structures. These macro rules are applied in inverse direction when the TL message is reconstructed.

This review of the literature is concluded with a brief review of some of the more accessible publications that provide an introduction of basic aspects and an explanation of the main issues in information processing in listening and speaking.

The book Cegnitive Psychology and its Implications by Anderson (1985) is a detailed introduction to cognitive science, dealing with issues such as the representation of knowledge, memory and learning, problem solving, and the structure and generation of language. More particularly the chapter dedicated to information processing as a method of cognitive psychology provides a description of information processing on an abstract level and within the framework of a computer analogy. Under the topics of perception and attention bottom-up and top-down processing as well as their interaction are subsumed and explained.

In addition to being a comprehensive introduction to all domains and issues of cognitive science Stilling's Cognitive Science (1987) also offers some insight into top-down and bottom-up 
processes in information processing. These are demonstrated in examples taken from visual perception and explained in a way that easily allows the transfer of the described mechanisms to spoken language.

Although Computers and Thought (Sharples, Hogg, Hutchison, Torrance, and Young 1989) is a practical introduction to Artificial Intelligence (AI), it provides an investigation of many general issues in cognitive science, ranging from the organization, storage, and access of knowledge to reasoning, models of cognition, and the philosophy of mind. Information processing systems are considered on a general theoretical basis in an attempt to explain the black box of the human mind.

The goal of Computers and Written Texts, edited by Butler (1992), is to demonstrate what kind of contributions computers have made to the study of natural language processing and to provide "an up-to-date survey which will, it is hoped, be accessible to those who already know something of applied language studies, but little about the computer and its use." (Butler 1992, vii) Based on a computer metaphor top-down and bottom-up processing are explained as the two basic parsing techniques, and the advantages, disadvantages and possibilities of successful interaction between them are discussed. In addition, the considerations of machine translation and natural language processing are of special interest to the subject of this thesis.

Last but not least a recent publication by Stevenson (1993) on Lanquage. Thought and Representation is a useful contribution to 
many issues dealt with within the framework of an information processing approach to simultaneous interpretation, including the representation of knowledge, language and information processing, comprehension of meaning, concepts, problem solving, expertise, creativity, and hypothesis testing. 


\section{CHAPTER III}

\section{A DEFINITION OF SIMULTANEOUS INTERPRETATION}

Ever since its official introduction during the Nuremberg Trials in 1945/46 the profession of interpretation has gained growing importance as a means of multilateral communication. While in the early days consecutive interpretation (Cl) was the more dominant form of oral translation, the simultaneous form is the one mainly used today in conferences, negotiations, debates, and many other types of international communication. In a world of ever expanding international relations simultaneous interpretation "a remplacé à la fois les linguae francae successives, latin ou français, et l'incommunicabilité de la Tour de Babel." (Lederer 1981, 16) [has replaced both, the successive lingua francae and the incommunicability of the Tower of Babel] (my translation)

The view that "your rendering will naturally tend to be verbatim" (Gerver 1976, 168) and that the simultaneous interpreter is "engaged upon the work of word-translation" (ibid.) reflects the attitude of the early days of SI that a word-for-word interpretation was the only possible way of translating a spoken message in one language simultaneously into another language. Much has changed since then and the following description of SI, its differences from 
and similarities to translation and consecutive interpretation shall help to shed some light on the process of SI, its nature and goals.

'Translation' is sometimes used as a generic term, referring to the process or result of converting information from one language or language variety with the aim of reproducing the original features of the source language message by finding equivalents in the target language, subsuming any kind of translation in the written, spoken or signed mode. However, researchers tend to narrow the scope of 'translation' down to the written mode. In this form translation has existed for a very long time, applied to transform written texts (literary, poetic, philosophic, political, etc.,) in one language into written texts in another language. While documentary evidence of translation can be tracked back for two millennia (Bell 1993), its scientific status as an academic subject in our epoch was established mainly with the work of Nida $(1964,1966,1974)$.

Interpretation, in contrast to written translation, is used to refer to the spoken mode or sign language translation, i.e., a situation in which an interpreter translates a spoken or signed message, performed by the 'speaker' of one language, into an equivalent spoken or signed message in the language of the 'listener'. The translator of written texts is usually not in direct contact with either the producer/writer or receiver/reader of the text, whereas the interpreter is present as a mediator while information is exchanged in conferences, law courts, and other situations that demand direct communication between two parties that do not share a common language. Although the term 'interpretation' includes, as 
has just been mentioned, the translation of spoken and signed languages, the term will be used in this thesis to refer to the spoken mode only, unless indicated otherwise.

In consecutive interpretation (CI) the interpreter listens to the speaker of the source language while taking notes and awaits a pause (which can occur after a longer paragraph or part of the talk) or the end of the talk to transmit the message to the listener in the target language, using the notes as a supporting technique to organize and synthesize the output. Note-taking during the listening process fulfills a double function: it serves as an external storage device and produces also essential indices for the organization and reconstruction of the message in the target language (di Vesta and Gray 1972). It can therefore be considered an external tool in active information processing. Although there is a tendency to favour notetaking in the target language, there is no clear consensus on the question whether notes should be taken in the source or the target language. Research has shown though that performance in $\mathrm{Cl}$ can be optimized by paying maximal attention during the listening process, making use of well-developed strategies of note-taking (e.g., use of symbols (Rozan 1956)) and the extraction of the focus of information as well as a high degree of automatization of parts of the process during listening, note-taking, analysis, and synthesis (Gile 1991).

In simultaneous interpretation, on the other hand, the interpreter only listens to the speaker, processes the message and produces the output in the target language simultaneously, i.e., the 
interpreter speaks one part of the message in the TL while simultaneously listening to the next part of the message in the source language.

$\mathrm{SI}$ is considered to be a special form of translation and innumerable definitions have been proposed for both, varying according to the focus on the nature of the task in question as a product, a process or a concept. In the field of translation, attempts to come up with a universally valid definition cause considerable problems and controversies. The wide range of definitions, often focusing on the question of priority for the retention of grammatical, lexical, stylistic or informational features, mirror the dichotomy between translation as an art and as a science as well as the corresponding diverging notions of 'equivalence'.

Among the features that many definitions have in common are some of those that are also relevant for Sl: a 'movement' of some kind 'from one language to another' and the attempt to find 'equivalents' that preserve 'features' of the 'original message'. Much of the controversy in translation arises from the attempt to define 'equivalence'. Such a definition becomes more complex and debatable with a growing diversity of text genres. Therefore the problem applies more to translation than to interpretation. The question of which features shall be preserved thus never was a major issue of controversy in SI since the early idea of simultaneous interpretation as a word-for-word translation has been abandoned. Even though the focus of what is most important in SI and the question of which are the outstanding characteristics defining the nature of simultaneous 
interpretation can shift from a more meaning-based to a more content-based approach, from a narrower to a wider interpretation.

According to the Ecole Superieure d'Interpretes et de Traducteurs (ESIT) at the Sorbonne University in Paris, which "s'est acquis depuis vingt ans la réputation enviable de former les interprètes les plus sollicités" (Lederer 1981, 21) [has over the last twenty years acquired the enviable reputation of training the most sought for interpreters] (my translation) and can therefore claim to hold one of the most influential views in the domain of interpretation, the interpreter's mission is to render the message uttered during each speech accurately and in full (Gile 1989). This view finds further expression in the descriptions proposed by the two main proponents at ESIT, Lederer and Seleskovitch. The latter (Seleskovitch 1976) stresses the identification of relevant concepts and their recoding in another language as the main issue in SI. The conveyance of a given meaning, regardless of the original wording, is at the heart of the process during which the interpreter simultaneously takes two roles of the common speech performance: that of understanding and that of rendering ideas.

Lederer (1981) argues along similar lines that the equivalence between the sense of the SL message and that of the TL message is of prime importance, and that this equivalence can be complemented by a TL style that should mirror the original style and must be compatible with the target language. What makes it possible for the interpreter to fulfill two tasks simultaneously is described as the 
conceptualization of the spoken and therefore evanescent $S L$ message into a souvenir cognitif (Lederer 1981, passim).

Isham and Lane (1993) describe SI as an act of transformation of sentences and their meaning from one language to another, a performance comprising "numerous concurrent cognitive activities." (Isham and Lane 1993, 242) They underline the fluent, continuous manner in which this simultaneous processing takes place as an ability that can occur in 'normal' bilinguals to some degree but is a specific characteristic resulting from extensive experience and training.

Hamers and Blanc (1989) view SI in terms of information processing as the decoding of a source language message and its encoding in a target language while the content of the message is kept intact. Massaro (1978) extends this definition by stating that

the simultaneous interpreter must decode the surface structure of the original message, map it into some abstract representation, take this same abstract representation and map it into a new surface structure, and finally articulate the translated message. (Massaro 1978, 299)

Although she mentions that the text segments of the TL message should be detached from the surface structure of the original message, Darò (1992) formulates the intention "Form, Inhalt und Prosodie korrekt wiederzugeben" (Daro 1992, 1) [to render form, contents and prosody correctly] (my translation) as the goal of SI. She sets the framework for an investigation of the process of SI by 
describing it as a complicated task involving the phonological, syntactic and semantic decoding, recoding, and quick verbal production as well as the simultaneous auditory control of the speaker's SL output and the interpreter's own output in the target language.

To summarize, Si can best be described as a process during which an oral message in a source language is translated into an equivalent message in a target language, possibly via a conceptual basis, with the perception and understanding of the original message taking place simultaneously with the reconstruction and production of the TL equivalent and the control of both input and output. The goal of this simultaneous process is primarily the preservation of a meaning or content.

Although translation and interpretation (in general) and SI (in particular) share mechanisms of bilingual processing they differ significantly in many respects. While translation in its narrower sense belongs to the written mode, interpretation takes place in the oral mode (or visual mode for sign language interpretation). SI is usually restricted to spoken language, whereas the consecutive interpreter makes use of the written mode to a certain degree during note-taking.

In interpretation, and especially in SI, an information flow has to be processed. Translation, on the other, hand comprises the double transformation of a permanently available text. Accordingly SI, more so than $\mathrm{Cl}$, is subject to severe time constraints, entailing the necessity of rapid decision making and a limited possibility of error 
correction. While long-term time management skills are indeed an important tool for the profession of the translator, there is no imminent time pressure.

The translator can, and does, rely on supporting techniques such as dictionaries or machine translation programs, sources of information that are generally not available to the simultaneous interpreter during the interpretation process.

The text that the translator transforms, though available at all times during the translation process, is usually decontextualized, i.e., the translator can, apart from his general, domain-specific, and linguistic knowledge, get cues only from the visually represented text itself. The interpreter, however constricted the access to other sources of information may be, can receive additional cues from the situational context (e.g., speaker or listener reaction in the form of gestures, mimic, intonation) in which the information exchange takes place.

The object of translation, the text, is permanently available as a whole, i.e., the entire message to be transformed serves as the context in which the units of meaning are identified and 'interpreted'. The analysis of units in SI, on the other hand, has to be based on preceding context, prediction and the interpreter's linguistic, domain-specific, and general knowledge, and has to be started almost immediately after the input has been received.

The permanent form of the text, which has been constructed, reread and reconstructed before its submittal to the translator, also permits the construction, organization, reorganization, and revision 
of the target language text as many times and as extensively as it seems appropriate or necessary. The evanescence of the spoken SL message does not allow the same procedures for SI. Moreover, the oral speaker input bears all the distracting and often confusing features of spontaneous speech, e.g., hesitations, pauses, phonological, stylistic or other idiosyncrasies and errors, and is often distorted by background noise, and allows revision or error correction of the output on the part of the interpreter only within very narrow limits.

The permanence of the written text and the evanescence of the oral message also point to differences concerning the importance of short-term and long-term memory (STM and LTM respectively). While STM is of crucial importance in SI, where the production constantly lags behind listening by four to five words on the average, and where no supporting techniques can be applied, LTM plays the key role in translation. Similarly the delay and the quantity of information that has to be processed call upon LTM in consecutive interpretation, where speed of translation is less important than memory for text. LTM is of course not totally irrelevant to $\mathrm{SI}$, as it is the structural component where concepts are believed to be stored. Quick and effortless access of LTM is as important for analysis and synthesis processes per se as it is for prediction and the distribution of attention in SI.

What seems to distinguish $\mathrm{SI}$ from translation and $\mathrm{Cl}$ as well as from more or less all other tasks in human performance is the aspect of simultaneity. From a communicative point of view this 
simultaneity manifests itself in the fact that the interpreter takes the two roles that are usually involved in a communication situation: that of the speaker and that of the listener. The interpreter's dual role is even complemented by a third one, that of the 'translator' or transmitter between the two original roles.

Listening and speaking simultaneously interpreters also make simultaneous use of two different codes. They analyze an input in one language, while, at the same time, synthesizing an output in another language.

It is the temporary simultaneity of comprehension and production, which occur in parallel during sixty percent of the time of interpreting plus the monitoring of the own output that make simultaneous interpretation a unique task. Considering this process from an information processing point of view it can be observed that not only do decoding and encoding take place simultaneously within the same 'system' (the interpreter) and constitute a permanent information flow, but also, that bottom-up and top-down processes occur interactively and simultaneously during the interplay of linguistic and mental systems in SI.

This continuous information flow from input/decoding to output/encoding via semantic representations, and the interactive functioning of bottom-up and top-down processes during the simultaneous processes involved, are the most outstanding characteristics of simultaneous interpretation and will build the basis of the following information processing approach to SI. 


\section{CHAPTER IV}

\section{AN INFORMATION PROCESSING APPROACH TO SIMULTANEOUS INTERPRETATION}

\section{CHARACTERISTICS OF THE INFORMATION PROCESSING APPROACH}

Cognitive psychology has for some time now been dominated by the so-called information processing approach which analyzes cognitive processes into a sequence of ordered stages, each of which reflects an important step in the processing of cognitive information from input to output.

This kind of abstract analysis of an information flow has also been described in terms of a computer analogy, providing a way of illustrating otherwise elusive internal cognitive structures and processes. The basic assumption is that computers, like the human brain, consist of multiple components that process the information flow of mental objects during the execution of a particular cognitive task step-by-step in a serial order. Symbols and formal processes represent the information and information processes they stand for. They can be studied as patterns and the manipulation of patterns and are carried out by a set of rules (algorithms). These have formal character and are themselves finite but define an infinity of results. 
Accordingly the typical components that minimally characterize an information processing system capable of analyzing and synthesizing information comprise a sensory information system receiving, filtering and storing information during initial processing, and one or more memory systems with abstract representations onto which the input can be matched and which in turn can be mapped into output symbols of the output or response system.

While the information flow usually proceeds from a stimulus (features) to larger units built from them in a bottom-up or datadriven manner, the interpretation of low-level units can also be determined or complemented by a top-down or concept-driven mode of processing. This processing is a function of general and contextual knowledge and its representation in memory. The possibility of an interaction of bottom-up and top-down processes during the information flow points to the fact that the order of processing from input to output is not necessarily a strictly serial one, but can be cascaded.

Although the process of simultaneous interpretation with its "numerous concurrent, cognitive activities" (Isham and Lane 1993, 242) from a sensory $S L$ input and its analysis to the synthesis and output of an equivalent message in a target language via a conceptual base of semantic representations lends itself to an investigation from the information processing point of view, very few attempts have been made to capture the complexity of processing in $\mathrm{SI}$ in these terms. 
This thesis investigates $\mathrm{SI}$ as a special case of multilingual human information processing, and attempts to bring together prior efforts to apply the information processing approach to interpretation and more recent findings in cognitive science concerning issues in information processing.

Taking place in short-term and long-term memory through devices for decoding a spoken message in a source language and encoding it into an equivalent TL message via non-language specific semantic representations, SI can be modelled as a set of complex skills that involve both bottom-up or stimulus-driven and top-down or concept-driven processes which are integrated by means of a style of operation that is cascaded and interactive.

Within this framework of information processing, the presentation of a model as an external representation and realization of theoretical aspects offers the advantage of revealing the significant characteristics and functional and structural components of the input-output process. It also introduces important issues (e.g., knowledge representation, attention) that are crucial to the investigation, understanding and training of simultaneous interpretation.

In terms of human information processing, any model must account for the following characteristics: the ability of the human brain to receive and transmit a continuous flow of often chaotic and distorted sensory stimuli; their conversion into discrete units of data; the fact that inherently meaningless signals can be converted into meaningful messages; the huge amounts of information that can 
be processed, stored, retrieved and reused; the cascaded interaction of bottom-up and top-down processes during analysis and synthesis.

Furthermore, a model is a good means of pointing out the manner in which the information processing system in question operates. In the case of information processing in SI it shows that interactive top-down and bottom-up processes work in a cascaded style (i.e., analysis and synthesis at one stage need not be completed before the next stage is activated and revision is permitted). This is of crucial importance to $\mathrm{SI}$ as the simultaneous, stimulus- and concept-driven processing of input and output does not allow for strictly serial, unilateral processing.

In addition, the specification of components and processes involved and of the relationships between them can help to uncover the weaknesses and limitations of the model and indicate topics for further research.

Technological and educational advance, especially in the field of SI training, could also gain from the development of a comprehensive model of information processing that applies to the interpretation of all spoken and signed languages.

No model that would attempt to put the findings of current research in cognitive science into an information processing perspective of $\mathrm{SI}$ has been proposed in recent years. The model proposed by Moser (1978) can serve as a basic guideline into which insights, findings and considerations of other researchers and of more recent investigations in cognitive science and interpretation will be integrated. As the simultaneous interpreter takes the role of 
the listener and speaker, i.e., analyzes and synthesizes in parallel, and simultaneously sixty percent of the time, the model has, as Moser (1978) points out, to be a complex and in places fairly complicated one.

Following the process from input and feature detection to primary and secondary recognition, word and word-string processing, the search and retrieval of language-independent conceptual representations, the production process and output in the target language, the focus of investigation will be on the detection and explanation of top-down and bottom-up processes and their cascaded interaction.

In order to illustrate the stages of processing, the various structural components, and the interaction between them a flow chart will be presented, providing on a global level a description for the sequencing of information in simultaneous interpretation.

Apart from the topics that will be raised in the course of the discussion of the model and which will be dealt with at relevant points, the following issues will subsequently be discussed in more detail: memory and the representation of knowledge in concepts; the question of attention and effort distribution; expertise in simultaneous interpretation.

Subsequent to these considerations of SI as a special case of information processing the implications of this point of view for practical SI, i.e., practise and training, will be discussed. 


\section{THE MODEL}

Performance in simultaneous interpretation begins with the SL stimulus and comprises a sequence of processing stages that are, although logically successive as one stage makes the information that it has processed available to the next stage, not strictly serial in terms of time.

The model shown graphically in Fig. 1 describes the information flow through the stages of analysis (feature detection, primary and secondary recognition), rehearsal, search for and retrieval of a conceptual base and activation of conceptual relations, and finally the synthesis of the output. The various functional components, which describe individual operations that take place at a particular stage, correspond to a set of structural components that refer to the nature of the information that is stored at a given stage in the process. Decision points during the process allow for loops via which prior stages can be reiterated in cases of insufficient or ambiguous information or if errors are recognized and parts or the whole of the process have to be retraced.

It is important to bear in mind that, while the flow of one chunk of information through the processing system is traced stepby-step, new information is almost constantly being received and processed in parallel. 


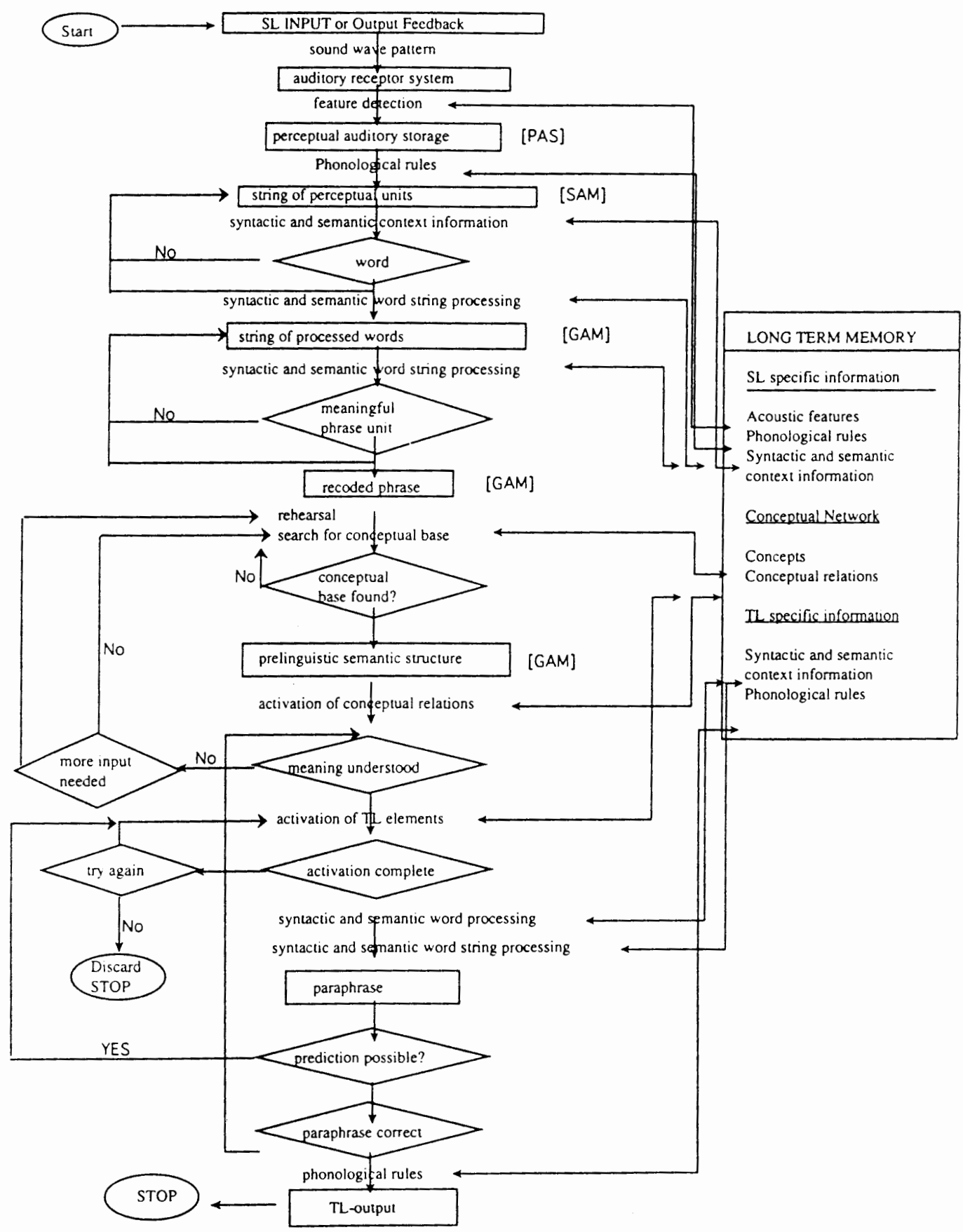

Figure1. An information processing model of simultaneous interpretation (adapted from Moser (1978)) 


\section{Feature detection}

When the sound wave patterns of the SL output reach the eardrums of the interpreter they are received by an Auditory Receptor System and become available for subsequent feature detection. Feature detection, according to Moser, is a mere match of incoming features against those stored in long-term memory (LTM) in order to find out whether a received acoustic feature is actually presented or not. After this readout process the information processed thus far is stored in Perceptual Auditory Storage (PAS)

Moser believes this early stage of processing to be strictly passive. This implies that all sounds that reach the ear are received and stored without being filtered or described in terms of characteristics. The assumption that has to be made here is that all acoustic stimuli, including background noise or voices of other speakers and interpreters, are received regardless of their source. If they are found to be irrelevant or fail to be matched against acoustic features stored in LTM, they are quickly discarded at the next stage in order to put a minimal strain on the interpreter's processing capacity. Feature detection can be assumed to occur even when listening to languages of which one has no command whatsoever.

On the other hand this stage makes it possible for the interpreter's own output to be 'reprocessed' again after having been uttered. This auditory feedback is, as Moser states, supposed to be a function of the available processing capacity. Good interpreters can 
manage their processing capacity to a certain degree, and therefore the process is not as passive as it would seem at first sight

Gerver (1976) describes this early stage as sensitive not only to the availability of $S L$ input and the momentarily available processing capacity, but also to individual input segmentation strategies.

Massaro (1978) holds the view that acoustic features are described in a continuous manner that indicates not simply whether a speech sound is present or not, but expresses the degree to which the quality in question is present. This is of great importance for the feature detection stage in case of low voice intensity of the SL input as well as in situations in which a speaker accent or some kind of speech impediment obscures or distorts the 'normal' features of the speech sound.

Lieberman (1963) found that a 'better' acoustic signal in terms of temporal properties also supports its identification.

On the whole feature detection appears to depend entirely on the stimulus that triggers it and can therefore be assumed to be strictly bottom-up.

\section{Primary recognition}

Primary recognition occurs either after feature detection of one pattern is accomplished, or while the acoustic features of a speech stimulus are still being assembled until the sound pattern is complete. 
The acoustic features stored in PAS for a quarter of a second at the most (Massaro 1978) are evaluated by being matched against the representations of perceptual units (signs or prototypes) which are stored in LTM. These perceptual units are likely to correspond to sound patterns of the size of a vowel or a combination of a consonant and a vowel as those, other than smaller units, can be described "by relatively invariant acoustic features" (Massaro 1978, 306) and fit into the restricted temporal range of PAS.

The synthesis of acoustic features into synthesized percepts (syllables) is based on the phonological rules of the source language. The perceptual units are then stored in Synthesized Auditory Memory (SAM), where they can undergo secondary recognition.

If the SL message is uttered and received in a very low voice or with obscured or distorted features primary (and secondary) recognition become very difficult for the interpreter and, given the fact that processing capacity is limited, can affect the speed and quality of further processing.

As the output of feature detection comprises the input for primary recognition the latter can be regarded as a bottom-up process that builds larger units from smaller stimulus units. Nevertheless the interpreter's awareness of the phonological idiosyncrasies of a speaker can result in a retrieval of the intended perceptual units even if the stimuli themselves did not correspond exactly to what is stored in LTM.

The expectation to hear a certain sound pattern can in some cases override a strict stimulus match with representations in LTM 
and be replaced by a synthesis of percepts that correspond to the expectation rather than to the stimulus stored in PAS. Therefore top-down processes can be assumed to play a role even at this early stage of processing.

If the stimulus has for some reason been distorted and only a part of the syllables that have been uttered can be identified, processing can still continue as there is the possibility that missing syllables can be restored subsequently by the occurrence of the socalled word superiority effect that can be observed in written as well as in spoken language recognition (see e.g., McClelland and Rumelhart 1981; Rumelhart and McClelland 1982). The word superiority effect describes the a posteriori result (in that case triggered by a top-down process) that the knowledge or expectation of a word may have on the recognition of its smaller perceptual units and will in the case of $S I$ help the interpreter to restore initially unrecognized perceptual units within the framework of the word context.

\section{Secondary recognition}

The strings of perceptual units that have been synthesized during primary recognition are stored in Synthesized Auditory Memory (SAM) for one to two seconds. This short-term storage is of great importance in $\mathrm{SI}$ as interpretation always lags behind the actual SL output and word identification must often be delayed because of poor listening conditions, insufficient context clues or a temporary lack of processing capacity. 
The perceptual units in SAM are transformed into words or meaningful units (Massaro 1978) through a match against lexicon entries in LTM that contain perceptual, syntactic and semantic as well as conceptual information. Two independent sources of information can be said to determine the word or concept that is finally retrieved: the syntactic and semantic context contained in the message and perceptual information in synthesized memory.

The emerging string of processed words is then stored in Generated Abstract Memory (GAM) available for further processing.

In addition to the syllable-by-syllable acoustic driven bottomup mapping of the information stored in SAM contextual constraints, general knowledge and lexical stress patterns play an important role during secondary recognition.

Preceding context facilitates word recognition in that it sets a framework for what the interpreter can predict concerning the semantic content and the syntactic class of a word.

In case of ambiguity despite preceding context and information provided by LTM, the interpreter can delay the identification across a number of words, and via a feedback loop to SAM wait for the next units to become available for processing of additional information. Even in the case of successful word recognition it is possible for the interpreter to loop back to the SAM and to check the result against subsequent information.

The use of lexical stress patterns for word identification is only successful if the speaker actually uses them correctly. Otherwise wrong stress patterns, e.g., due to accents or dialects, 
may be misleading for the interpreter and increase ambiguity, which has to be resolved by applying contextual information or by looping back to SAM.

World knowledge or domain-specific knowledge exceeding the immediate context as well as linguistic knowledge can complement word identification or make up for insufficient semantic, syntactic or immediate contextual cues.

Secondary recognition can be said to be guided by two manners of processing: (1) bottom-up, the stimuli being provided by the string of perceptual units generated during the previous stage, and (2) top-down, using $S L$ specific linguistic and contextual information as well as general and domain-specific knowledge that exceed the immediate context.

This model assumes an experienced interpreter who will ideally delay the act of actually translating the piece of information until the search for the conceptual base and the activation of conceptual relations are completed. However, it has been observed that beginners in SI often start the translation process as soon as word recognition has been completed. On the one hand, this is due to the fact that they use less efficient chunking techniques, and on the other hand, they have not yet explored the capacity of their SAM or lack strategies to quickly retrieve information from it after a delay. Novices are also likely to be overcharged by the task of simultaneously listening and speaking and have not yet developed efficient strategies to integrate contextual information. For better or worse they often also depend on the structure of the SL input for 
the reconstruction of the message in the TL and accord importance to equivalence of words and structure rather than to meaning and content. How these and other difficulties can be overcome shall be demonstrated in more detail in Chapter $\mathrm{V}$ which deals with the implications of an information processing approach to SI.

\section{The Generated Abstract Memory (GAM) stage}

The Generated Abstract Memory (GAM) proposed in the model corresponds, according to Moser (1978) and Massaro (1978) respectively, to what elsewhere is often referred to as Short Term Memory (STM) or Working Memory (WM). It complements Sensory Memory and Long Term Memory and is the crucial structural component of the stage at which continuous rehearsal and recoding operate.

The verbal information available at this stage can be processed further or stored here temporarily. The storing capacity of GAM is assumed to be limited but variable, as it depends on the capacity that was necessary for processing at the previous stages. The smoother and more effortless the processing up to the stage of GAM, the greater the GAM capacity. Some researchers, e.g., Moser (1978), describe the size of the latter in general to be seven plus/minus two chunks, while others, among them Massaro (1978), believe it to lie between three and seven chunks.

Temporary storage at the GAM stage is of crucial importance in simultaneous interpretation, as the fact that an output has to be generated causes the delay of immediate input processing. GAM can 
be viewed as an intermediate working component that is involved in the recoding of the surface code of the source language into that of the target language. The size of the units recoded is very likely to be larger than a word. Word-by-word recoding would in most cases fail to resolve ambiguities that can easily be tackled within the larger context of preceding and subsequent information.

Once syntactic and semantic word processing have yielded a meaningful phrase unit, if necessary via a feedback loop, the recoded phrase can be further processed.

In addition to the following context, made available through looping back, previous context can determine the question whether or not a phrase unit is meaningful or not. Another possibility of topdown processing at this stage consists of the use of world knowledge and domain-specific knowledge that may help to answer the question just mentioned and to dissolve occurring ambiguities that lead to the occurrence of more than one possible responses at this stage.

The role of syntactic and semantic knowledge storage in LTM is not only important for syntactic and semantic string processing, but also for the subsequent stages during which a conceptual base has to be retrieved, conceptual relations activated and the TL message generated and produced.

While syntactic information is language-specific, semantic information is believed to be language-independent. Consistent with the tradition of generative semantics Moser (1978) describes the relation between the two types of information as interactive, i.e., 
syntactic and semantic information work together towards the correct processing of input and output and the resolution of ambiguities.

Up to the GAM stage, the bottom-up mode of operating plays a strong role due to the fact that larger units are assembled from smaller ones ( features --> syllables --> words --> strings of words). Subsequent stages depend on this kind of process, too, in as far as the input to a stage in question triggers the next stage, i.e., functions as a stimulus. Yet concepts (in the conceptual network) as well as context and knowledge, come to play a more important role during recoding and rehearsal, allowing top-down processing to dominate and override the results of stimulus-driven processes, and even initiate the elimination of all stages of input processing between feature detection and the activation of target language elements.

As the feedback loops in the flow chart indicate, rehearsal and recoding are continuous processes that 'translate' the syntactic and semantic structures of the SL message into abstract forms which are subsequently recoded into the TL message. Rehearsal and recoding are described as "the workhorses of the simultaneous translation task . . . unique relative to normal language processing." (Massaro 1978, 310)

The meaningful phrase units now available in GAM trigger the search for a conceptual base, which consists of the concepts themselves and formal relations between them. The bottom-up initiation of the search is continued in a combined top- 
down/bottom-up manner, as the activation of one concept will entail the activation of relations to other related concepts and finally the retrieval of the appropriate conceptual base and the corresponding TL elements.

While there are innumerable definitions for 'concepts' and many views on their exact nature and structure, there is agreement that concepts are crucial for the representation and organization of knowledge within the framework of an information processing approach.

One of the most salient features of concepts seems to be their multiple coding with both language-specific information about linguistic form and function as well as abstract, languageindependent semantic information. Relations occur between (a) clusters of concepts, (b) individual concepts, and (c) different nodes within a concept.

All information stored in concepts as well as the relations within and among concepts are variable and therefore subject to alterations through learning processes. The network of concepts that emerges can thus be constantly changed and the possibilities of extending it are limitless.

Furthermore concepts are assumed to be connected to lexical units (words). These connections are intralingual, i.e., they link a word with a concept in one language, and interlingual, relating language-specific nodes of the same concept. Despite the attachment of language-specific codings, the concepts themselves as well as their combinations through relations and in clusters are 
language-independent. They can therefore be said to be universal as far as their abstract contents are concerned.

The nature of concepts as it has been described can account for the way in which the input is further processed at the stage at which the conceptual base is retrieved. The the input processed up to this stage stimulates the activation of concepts and nodes. At the same time context and knowledge can determine the search. They can even override the results of the stimulus-driven process if the stimulus is not consistent with expectations or if ambiguities occur. In the latter case a backloop can provide more contextual information and help to resolve ambiguities as 'wrong' solutions are eliminated or new, more relevant concepts are activated.

Once an appropriate prelinguistic structure has been found, conceptual relations are activated, stimulated by the retrieved conceptual base. They can in turn activate other links among and within concepts. Here again the information provided by preceding context and special as well as general knowledge can complement the process that finally leads to a "subjective feeling of understanding" (LeNy 1978, 292).

If the meaning of the processed unit is not yet understood or ambiguities persist, more input is possibly needed. This can be gained by going through the rehearsal loop, initiating the processing of information recoded in GAM. Another possibility is a new search for an appropriate conceptual base, which will again be determined by the stimulating recoded phrases in GAM as well as by preceding 
context, knowledge and the information furnished by continuous rehearsal.

\section{Synthesis and output}

When most or all of the meaning of the SL input has been understood, the appropriate TL-elements are activated. This is possible due to the dual nature of the connections between concepts and words, which are both inter- and intra-lingual. This means that SL and TL expressions are linked to the relevant languageindependent concept and that there is also a connection between the SL and TL nodes of one concept.

Although the input of this stage is provided by the previous one (unless prediction has led to its elimination) and serves as a stimulus, the activation and retrieval of the TL elements is literally 'concept-driven'. It is also determined by what the interpreter knows about the TL, the intentions of the original speaker, the listener's expectations, the specific domain and the world in general.

Once TL elements have been activated, the processing can continue if the activation seems complete. Otherwise there is the possibility to loop back ( repeatedly if necessary and if enough processing capacity is available) and retry the activation of TL elements, using more available information from subsequent stages as stimulus. If the activation of TL elements can nevertheless not be completed (i.e., the equivalent TL elements, despite input stimuli and top-down processed knowledge or prediction, can not be sufficiently activated or retrieved) the current unit of processing 
has to be discarded and is 'lost'. The same consequences will occur when not enough processing capacity is available to go through the 'try again' loop.

When activation can be completed, the TL elements are syntactically and semantically processed according to TL rules until a paraphrase for the SL input is found. Here again preceding context, linguistic, domain-specific and world knowledge, complement the process in a top-down fashion.

The importance of the ability to make valid predictions from the preceding context or on grounds of linguistic, domain-specific or general knowledge, is put into perspective by the fact that almost all stages of processing that lead to the understanding of the meaning of the processed input can be eliminated. If the interpreter can predict what is to follow, the activation of TL elements can be initiated immediately and current input can be discarded. According to Moser (1978) effective semantic and syntactic organization facilitate the prediction of form and content, saving much of the limited processing capacity and making it available for other, more complex or demanding processes. It can be assumed that prediction is a function of the fact that the knowledge represented in concepts can be used in a top-down fashion to skip most of the preceding stages of processing. It is also a function of the speed with which conceptual relations are activated and of the number of links that are thus stimulated. If this is what lies at the heart of efficient processing in SI, then the objective of every interpreter and training program should be the establishment of as many concepts and 
conceptual relations as possible and of strategies that support their quick and efficient activation.

To sum up the considerations concerning the predictability of subsequent input, it can be stated that the question of whether prediction is possible or not depends on the interpreter's linguistic competence, the ability to draw conclusions from the immediately preceding and the wider context of the discourse. The speed and quantity of concept retrieval and of the activation of conceptual relations as well as the individual criteria of the interpreter in deciding whether or not to take the 'risk' of saving processing capacity by predicting are further important factors in that context. The structure of the languages involved (see discussion of 'case grammar' and its consequences for prediction in $\mathrm{SI}$ in the section "Memory and knowledge representation" in this chapter, and in Chapter VI) is another potential factor to play a role in the use of the prediction mechanism.

Although prediction is to some extent based on the stimuli that have just been processed and those processed earlier, subsequently providing an immediate sub-context, the more important manner of processing at this stage is the top-down one, i.e., prediction on grounds of knowledge and context.

Before the target language output is finally uttered, the retrieved paraphrase of the $S L$ input is double-checked. It can be delayed, altered, or even discarded altogether, if renewed processing (from the 'meaning understood' decision point or even from a further rehearsal loop) yields a more appropriate solution. A retry that does 
not lead to any satisfactory activation of TL elements or a lack of time/capacity to retry again will entail the same consequences.

The application of the phonological rules of the TL finally lead to the utterance of the spoken TL output. This theoretically brings the processing of the chunk in question to an end.

\section{Auditory feedback and output correction}

Interpreters normally hear not only the voice of the speaker but also their own output. Whether, and to what extent the interpreter's output is processed in the same way as the original SL output depends primarily on the availability of processing capacity, in particular, storage capacity in GAM. If the processing of the speaker input has been difficult (e.g., if the voice quality of the input was poor, if the speed of input was high or if the interpreter had difficulty in retrieving the appropriate TL equivalent), then little processing capacity is available for auditory feedback. In that case interpreters will process their own output only as far as the stage of feature detection. A committed error will in that case go unnoticed by the interpreter and will consequently not entail a correction of the TL output even if a correction would be appropriate.

Alternatively, if enough processing capacity is still available the interpreter's output can be further processed to SAM. In cases where the reprocessing stops at this stage errors will still not be noticed (as they are not processed for meaning) and the stored unit will decay within one to two seconds. 
Ideally the remaining processing capacity should allow the continuation of the process until the TL output is stored in GAM for fifteen to twenty seconds. During this time the TL output remains available for further processing (for meaning) or for comparison with previously or subsequently processed chunks. If the renewed processing yields other solutions, possibly due to information that can be gained from more context or the activation of different concepts and conceptual relations, the original output can be corrected.

\section{SOME THEORETICAL CONSIDERATIONS}

\section{Attention and processing capacity}

Although the model introduced above was used to demonstrate information processing in simultaneous interpretation as a serial succession of stages, the various steps actually overlap and processing takes place at all stages during the interpretation process. This simultaneity demands that the interpreter's available attention or processing capacity, which is variable but limited, must be distributed in some way. Only if the available capacity is allocated efficiently, especially when individual stages of processing are extremely difficult and demand more attention, can the successful processing from input to output be assured and a breakdown prevented.

Gile $(1985,1991 a)$ has proposed a modèle d'efforts (effort model) of $\mathrm{SI}$ that explains how finite attention is shared as required 
by all the tasks involved. The model in question also provides explanations for a variety of problems that typically occur during information processing in SI.

Three different sets of operations or 'efforts' are distinguished:

(a) $L=$ listening to and analyzing of the $S L$ input, i.e., all mental activities involved in the perception and comprehension of the input

(b) $P=$ producing the TL output, i.e., the effort needed to put the information to be reconstructed into its linguistic form

(c) $M=$ memory or storage in and retrieval from short-term memory for strategic or linguistic reasons.

Depending on the task each of these efforts $(L, P, M)$ has a certain processing capacity requirement $R$ (LR, $P R, M R$ ) and a particular amount of capacity $A$ is available for each of them at any point in time (LA, PA, MA). The sum of these individual requirements is TR, that of the particular availability TA.

If the process of $\mathrm{SI}$ is described as the sum of the three 'efforts' (i.e., $S I=L+P+M$ ) then there are two conditions to be fulfilled in order to perform SI:

(1) $L R+P R+M R=T R<T A$

This means that the sum of the individual requirements must be less or at the most equal to the total availability of processing capacity.

(2) $L R<L A$

$\mathrm{PR}<\mathrm{PA}$ 


$$
M R<M A
$$

In other words, each individual requirement must be less or equal to the individual availability.

Difficulties or breakdowns during the interpretation process occur when TR > TA, i.e., when the total requirements exceed the sum of available capacity, or when any of the individual requirements is bigger than the capacity available for this operation. The former is the case when SL input is very fast, dense or distorted and relatively too much processing capacity has to be devoted to the listening and production process, not leaving enough MA. Similarly a great syntactical discrepancy between the source and the target language may require long storage times in Generated Abstract Memory before the SL input is restored, thus using much capacity for $M A$ and leaving insufficient $L A$ and PA.

In cases of a momentary laps of attention (e.g., due to fatigue) the individual requirements are likely to be higher than the corresponding availability factors as the interpreter will make efforts to 'catch up' on what was missed.

Within the framework of this effort model, the importance of prediction becomes more salient. If the interpreter can anticipate the input to come, much processing capacity is saved and becomes available for other, possibly more difficult parts of the process.

Although Gile (1991a) states that processing capacity "is not dependent on extraordinary linguistic knowledge or skills, overall 'intelligence' or general and specialized knowledge" (Gile 1991a, 16), it seems that the significance of top-down processes increases in 
situations where not enough processing capacity is available for a certain stage. If, for example, the processing of syllables into words is made difficult by an incomplete or distorted input, a thorough knowledge of the language and domain in question may help to restore the missing elements of the stimulus, thus saving processing capacity that would otherwise be spent on longer storage. Likewise the activation of target language elements can be initiated by prediction, eliminating preliminary stages of processing and saving valuable processing capacity. Reinforced processing efforts at any stage during the process will necessarily entail a deficit in available processing capacity at other stages. They may lead to a breakdown as the interpreter will have to struggle with difficulties at different stages, and may not be able to make up for losses of information or blanks during the process.

Facilitation of information processing due to an efficient management of processing capacity supported by top-down processes can of course only occur if the use and integration of concept-driven processes happen smoothly and almost effortlessly. This will only be the case if knowledge represented in LTM is easily accessible and organized in a way that allows quick retrieval and if the information thus gained can be integrated with bottom-up information with relative ease.

As processing capacity is variable, depending not only on the interpreter's personal condition, quality of input and individual performance criteria but also on expertise and practise, it is subject to improvement through training. Whatever the form of the 
exercise and practice chosen, the goal should be the development of strategies of efficient processing capacity management and a decrease of the standard effort requirements.

Gile does not indicate how the management of efforts is actually regulated or supervised. It is conceivable that it operates in terms of a self-regulatory mechanism. Another possibility is the assumption of the existence of what is referred to as the Central Executive in contemporary research literature on memory.

\section{Memory and knowledge representation}

Many contemporary models of memory (e.g., Morris and Jones 1990; Baddeley 1992; Gathercole and Baddeley 1993) that stand in the classic tradition of a serial symbolic approach to knowledge representation include such a Central Executive (CE) in their description of a multi-component Working Memory. The CE is assumed to be a general, central system that controls the processing and temporary storage of information when varying cognitive tasks are being executed (Van der Linden, Coyette and Seron 1992). The tasks of this CE comprise the control of the subsystems of Working Memory, its regulation and the integration of modifications in real time. Furthermore, it is responsible for choosing and organizing various processing tasks, for allocating processing capacity and for integrating the information provided and finally for providing storage used during rehearsal. While the latter two are part of the responsibilities of GAM in the model presented earlier on, a CE can also account for the distribution and control of 
processing capacity, the co-operation of the various subsystems and the integration of the outcome of processing at various stages.

As far as the organozation of memory into subsystems is concerned, the model adapted for this thesis represents the serial symbolic view of memory. This approach is characterized by a modal set of three types of memory: a sensory or echoic memory, shortterm or working memory (STM or WM) and long-term memory (LTM). Sensory memory (in our model PAS and SAM) and STM (GAM in our model), with their limited storage capacity that expands only over a short time and is easily accessible, are crucial to processing in SI. However, it has been demonstrated that top-down processing and LTM are also of great importance for the smooth and efficient execution of the operations leading from source language input to target language output via semantic representations. Therefore, the representation of knowledge in LTM is a phenomenon that has to be considered within the framework of SI in order to explain the access and retrieval of information stored there.

As mentioned before, knowledge in LTM is assumed to be symbolically represented by concepts. The classical as well as the probabilistic view of concepts is based on the assumption that a concept can be fully described by a set of necessary (classical view) or characteristic features (probabilistic view). The currently prevailing view is a theory-based one, emphasizing that the apprehension of theoretical relations between concepts is an important part of the meaning of a particular concept. The sharing of features among concepts represents the causal relationships that 
underlie our knowledge of a concept. These links that connect nodes of a concept, different concepts, and clusters of concepts contribute to the establishment of a semantic network.

The idea of a hierarchical order of concepts and nodes has largely been abandoned, and the revised version yielded a model that emphasizes the notion of spreading activation. It is assumed that at any point in time each node in the semantic network has a certain level of activation that spreads to related nodes and concepts until a part of the network becomes available to attention because it has a high enough level of activation. Activation of the entire knowledge base is prevented by the fact that activation weakens while spreading and that the level of activation at a node fades quickly over time. Nodes and relations that are activated more often than others are more easily accessible and can therefore be retrieved more easily. This also explains the observation that experienced interpreters process with less effort, especially within a special domain, as many of their concepts and conceptual relations are frequently activated and therefore easily accessible. It also confirms Moser's (1978) assumption that the more an interpreter knows (about a language and the world) the easier the task, as more and 'stronger' relations will be established within and between concepts.

Moser (1978) brings up the question of "which concepts have a larger number of relations to other concepts or clusters of concepts" (Moser 1978, 360) and relates it to Fillmore's (1968) Case Grammar. Fillmore observed "that the various grammatical relations in English 
bear only a very loose correlation with semantic roles" (Comrie $1989,58)$ and assigned a central role to the verb: the power to determine which 'case' or label (representing various points along a continuum of semantic roles that are characterized by a degree of control) can be assigned to it. In SI this would entail the assumption that the verb takes the dominant role, bearing manifold relations to many other concepts. This point of view can offer a powerful explanation for the fact that interpretation from verb-late languages (e.g., German) is often perceived as more difficult to translate orally, as the 'main concept' is not available for a considerable amount of time and predictions can be made only at a fairly high risk. On the other hand, given the freedom that the interpreter enjoys in recoding the message in comparison to the translator of written texts, the early occurrence of semantic roles referring to the concept of agents (the next most powerful concept after verbs) offers a possibility for prediction on the grounds of these concepts while the TL verb may then be chosen according to the agent. It should be mentioned though that not all researchers in the field of $\mathrm{SI}$ agree with the view that the interpretation between some languages or language pairs is more or less difficult than between others, and believe that neither the nature nor the structure of the languages involved play a role in explaining difficulties in practical SI. This is discussed in more detail in Chapter V.

Within the framework of the model it has also been pointed out that concepts carry language-specific information for $S L$ and $T L$ equivalents and that these nodes are also interconnected. This 
description accounts for the activation of $T L$ elements once a conceptual base has been found and conceptual relations have been activated. It can also explain why experienced interpreters usually have little difficulty with this process and why 'normal' bilinguals know equivalents in their two languages but have difficulty translating and interpreting with ease. The former group has, with years of practise, established complex and strong links between concepts as well as between language-specific nodes and can activate corresponding elements quite easily, but the latter has to put much effort into constructing relations and activating equivalents. Support for this model of concepts and conceptual relations also comes from research by Paradis (1985), who observed the so-called phenomenon of alternate antagonism with paradoxical translation behavior in bilinguals. This phenomenon is characterized by an alternate inability to access one language system, while the other is available for production. In addition paradoxical translation behavior manifests itself as the ability to make spontaneous use of the language into which the patient is unable to translate, and the simultaneous inability to use the language that is available for translation for spontaneous production. Paradis's observations seem to confirm the organization of knowledge in language-independent concepts and interrelated language-specific nodes linked to them, as such a model can account for the access to one language via translation only while the link between the concept and the $T L$ is inhibited. 
The question of how exactly two (or more) sets of linguistic codes are differentiated in order to allow for the retrieval of the form in the appropriate language is related to the general discussion about the organization of more than language in one brain. Even if one supposes, as described above, that corresponding languagespecific nodes are attached to a language-independent common concept, the question remains how the right language is chosen or activated. Within the framework of the chosen approach it can be assumed that there is no such thing as a pre-attentive language switch. This means that both language systems are activated together with the corresponding concept during speech processing and lexical analysis, but that memory in bilingual or multilingual individuals is dually (or multiply) coded. This proposition is consistent with current research in psycholinguistics and information processing (e.g., Paivio and Lambert 1981; Potter, So, VanEckhardt and Feldman 1984). The question of how the equivalent in the correct language is retrieved, especially in case of multilinguality when more than two language-specific nodes will be attached, has barely been investigated so far. Some insight into the mechanisms underlying the process in question might be gained from so-called dynamic models of activation and inhibition (e.g., Sternberg 1985; Berg and Schade 1992) that are based on the assumption that the more activation one node has accumulated, the more inhibition it will send out to 'competitors'. In the case of SI this would mean that, as the interpreter knows that he has to analyze an input in one language while producing his output in 
another one, TL elements will be subject to stronger activation, inhibiting equivalents in the SL (or any other language available to the interpreter). This model can also account for the phenomenon that, in cases where the TL element is not available or insufficiently activated as connections to the relevant concept are weak or not existent, the SL equivalent (or an equivalent element of another language) is chosen and possibly 'adapted' to the TL mode by applying TL phonological rules to it.

\section{Expertise}

According to Anderson (1985) the acquisition of expertise is mainly based on the application of automatized procedures instead of deliberate strategies that are used by novices. Although it seems clear that expertise has to be described by non-automatized special strategies and the effects of a wide conceptual knowledge, automatic processes do play an important role in expert interpreting and should be considered within an information processing approach.

One characteristic of expertise is described as the superiority at perceiving patterns (Anderson 1985). Especially within a special domain the experienced interpreter will be able to view certain expressions and phrases as patterns which can be used to activate corresponding TL elements immediately. Novices, on the other hand, will have to go through all stages of processing before they understand the meaning of the unit to be encoded and can retrieve the TL elements. Such pattern recognition is important and 
facilitates information processing in $\mathrm{SI}$, but is certainly not all that is necessary for the task.

As has been demonstrated with the model, the processing of information follows a set sequence of pre-established routines. A smooth succession of the operations involved is typical for interpretation experts, while novices have difficulty in following or establishing a similar set of compiled procedures that they can follow in order to process the input and synthesize the output.

Whether the automatization of sub-processes is, as Anderson (1985) assumes, a transition of declarative to procedural knowledge may be subject to discussion, as it can be observed that even complex tasks, such as SI, may well become automatized without ever having been explicit. It seems conceivable though, that novices follow the process, imagining step by step what they have to do in order to arrive at an appropriate TL output, whereas experienced interpreters 'just do it' without thinking about the process itself. This kind of automatization applies to listening, analysis and synthesis in SI and may also explain why, according to anecdotal evidence, interpreters with a long professional record can interpret while writing letters or knitting.

Expertise is also assumed to be domain-specific. However, this may apply less to SI, as good interpreters will possibly be at their best when interpreting within a special subject domain and between their habitual $S L$ and $T L$, but will also be able to transfer many strategies and procedures to other domains or even to different languages. It is also conceivable, and research has demonstrated this 
effect to a certain degree (e.g., Ericsson and Polson 1988), that some expertise, such as the efficient use of LTM, can be transferred to completely different tasks.

Experts are said to make more use of productions, while novices are believed to rely mostly on declarative knowledge, which in turn is used by experts in a different way. The increased use of a means-end analysis by beginners in SI mirrors a fortified application of bottom-up strategies and a lower STM capacity. Experts, in contrast, make more use of top-down processing, tackling the problems they encounter from a broader overallperspective rather than by viewing individual subsets of the problem that have to be solved.

One outstanding characteristic of expertise is the speed with which experienced people solve problems. This applies to $S I$ in the sense that expert interpreters will need less time to interpret the same input than will novices. The reason for this can be found in the automatization of parts of the process, the different representation of knowledge (i.e., more complex concepts, more conceptual relations and greater ease of activating them), the efficient use of STM and LTM and possibly a wider domain-specific and general knowledge. All these characteristics are to a great extent the function of practise and repetition. 


\section{CHAPTER V}

\section{IMPLICATIONS OF AN INFORMATION PROCESSING APPROACH FOR PRACTICAL SI}

\section{PREREQUISITES}

As the simultaneous interpreter has to process information in two (or sometimes more) languages in a quick and efficient way, bilinguality, or at least a near-bilingual command of the languages involved, is a mandatory prerequisite for the profession. Bilinguality is also supposed to have "the effect of providing them [the interpreters] with special forms of intelligence, sensitivity, and skills at teasing out what is meant and what is left half said." (Lambert 1978, 132)

Usually a distinction is made between an interpreter's active and passive languages. The former refers to the mother tongue or a native-like competence and performance in the production and perception of a language, while the latter describes the ability to perfectly understand a language in which production is fluent and correct, but not necessarily native-like.

Related to the issue of linguistic competence and bilinguality is the question of whether it is better to interpret from or into one's mother tongue. Interpretation from the mother tongue has the advantage of processing the source language input with ease, even 
under adverse conditions, thus facilitating and speeding up input analysis and understanding while leaving more processing capacity available for synthesis and output. Interpretation into the mother tongue enables the interpreter to quickly and efficiently synthesize the target language output. On the other hand, translating into a native or active language will often be related to a relative difficulty in effectively processing the SL output in the passive language, especially if the input is dense, fast, or distorted. Similarly, interpretation into a passive language may show deficits during synthesis and output, as TL equivalents may be less readily accessible, or not existent in the exact form required, and syntactic processing in the TL will put an additional strain on the task.

Pinhas (1972) has pointed out that political and economical spoken texts are often highly redundant in content and form. He suggested that in dealing with these interpretation from a passive language into the mother tongue may be preferable, as the customary difficulties of input processing are alleviated by redundancy, while the advantages of the active language for synthesis and output persist. Scientific and technical speeches, however, are described as a linguistic input "where more often than not every word has to be accurately perceived." (Gerver 1978, 1976) Accordingly, interpretation from the mother tongue seems to be advisable in those cases, in order to assure efficient and correct input processing.

Some researchers (e.g., Schweda-Nicholson 1992) also point out that interpreters working towards their dominant or active 
language can, due to a partly automatized production process, take advantage of being able to focus on meaning extraction from the $\mathrm{SL}$ input, and have to pay little or no attention to prosody when uttering the TL output. Consequently the interpreter will have to spend less time monitoring the output, and will be able to devote more time and effort to other stages of the process.

Many institutions and bodies subscribe to either of the two approaches. Lomonosov University in Moscow for example, promotes interpretation from the mother tongue, while at United Nations meetings and the Ecole Superieure d'Interpretes et des Traducteurs (ESIT) in Paris the focus is on interpretation into active languages.

Another question concerning the bilinguality issue in $\mathrm{SI}$ is whether any special kind of bilingualism equips the interpreter with preferable prerequisites for the profession of simultaneous interpreter. In addition to the difficulties of measuring language dominance and of monitoring the way of language acquisition in adult interpreters subsequently, there is no clear consent on the possible advantages of coordinate, ascribed, or early bilingualism over compound, achieved, or late bilingualism. Drawing conclusions from experiments (e.g., Vaid and Lambert 1979) that have shown that early or child bilinguals rely more on semantic processing strategies than late or adult ones, one might speculate that early bilinguals possess special abilities that help them perform challenging cognitive tasks as they occur in SI. There is evidence (e.g., Ben-Zeev 1977; Pattnaik and Mohanty 1984) that child bilingualism in particular promotes a higher level of creativity and 
verbal skills, the ability to reorganize information and a higher degree of metalinguistic awareness. Considering that all these qualities play a role in information processing in $\mathrm{SI}$, there is reason to suspect that early bilingualism equips interpreters with some important tools for their profession. It cannot, however, be concluded that interpreters who have become bilingual as adults do not possess these special abilities or cannot acquire them at a later stage.

The necessary abilities of calling up ideas and rapidly retrieving the right expression from a restricted area of meaning, which characterize swift information processing in good interpreters, are combined in the term verbal fluency (Carroll 1978). It is supposed to be correlated to the ability to "store, retrieve, and manipulate elements of information." (Hamers and Blanc 1989, 253)

In addition to highly developed language skills in two or more languages, interpreters who have to deal with a very complex and cognitively demanding task are also expected to possess outstanding cognitive skills, including a high flexibility and a strong memory factor (Gerver, Longley, Long, and Lambert 1984). Furthermore, a diverse cultural background and broad general knowledge will facilitate the task of interpreting between speakers of very different languages, cultures, and thematic domains.

As SI takes place in a situation that resembles in many aspects a 'normal' communication situation, in which spoken language is used among participants who are present at the time of information exchange, the interpreter must also possess the ability 
to integrate gestures, tone, etc., into his interpretation. This latter ability refers to the semiotic aspect of language that exceeds the spoken sign.

As the task of simultaneous interpretation demands special attention and concentration under severe time constraints and often very stressful conditions (e.g., noisy background, fast and dense input), which can impair the flow of information processing at any stage, one of the major personality requirements for the successful interpreter is the ability to deal with stress. A study carried out by Gerver (1974) led to the observation that high anxiety--a drawback under extremely stressful conditions--can be advantageous in situations that are only moderately stressful. In the latter case a high anxiety factor will bring the interpreter to focus attention, optimize the management of processing capacity, and to push individual performance criteria to a high level. Extremely stressful situations on the other hand may cause a very anxious interpreter to perform poorly or to break down under the strain and pressure. A potential subject for further investigations, the importance of the interpreter's personality for information processing is as yet a matter of common sense conclusions and speculation rather than the outcome of scientific investigation.

Although the interpreter needs a thorough understanding of the subject matter of the conversation to be translated, it is not necessary to be an expert or specialist in the topic in question. The interpreter has to be able to understand, not to explicitly express a personal opinion. Nevertheless, the interpreter has to be able to 
understand what the speaker wants to convey and what the actual message is. It is not necessary to have a specialized knowledge equal to that of the speaker, but to understand the topic, the problems, and special issues related to it, in order to quickly realize the main issues and to relate the original message to the listener in an intelligent way and in a style and manner that match the original speech as well as the subject domain. In other words, the more the interpreter knows about the topic in question, the quicker the original message will be analyzed and the target language equivalent synthesized. The output will also be more reliable and competent, as special subject knowledge will enhance the input and facilitate the use of special mechanisms such as prediction. This is why today interpreters have become more and more specialized, and why many agencies, companies, and institutions demand that the interpreters employed by them are not only multilingual but also have a good specialized knowledge and experience of the domain they are working in. However neither excellent subject knowledge nor a perfect conference preparation can guarantee a good interpretation, although both are important prerequisites.

\section{SL INPUT AND ANALYSIS}

It has been shown in the previous chapter that information processing in simultaneous interpretation depends on two ways of converting the input in one language into an equivalent output in another language: top-down and bottom-up processing. The SL input 
provides the initial basis, the 'bottom', for the subsequent processes. Although top-down processes play an important part in analyzing and synthesizing, the whole process of interpreting depends heavily on the nature, quality, and quantity of the input provided by the original speaker. As the SL input is usually formulated in a language that is not the interpreter's mother tongue, the following issues are of great importance in practical SI: the input rate; the text type of the speech and its density, redundancy, and special characteristics such as the use of figures or proper nouns; the loudness and clearness of the speaker's voice; general listening conditions in the environment provided for the interpretation situation; accents or dialect forms in the speaker's output; the idiosyncrasies of the actual source language itself; and, last but not least, the chunking of the SL input.

\section{SL input rate}

It has been observed, by researchers as well as by practising interpreters, that both exceedingly fast input that is packed with information and extremely slow and monotonous speech are difficult and stressful to process for the interpreter. The former is often incompatible with the interpreter's memory and processing capacity and will most likely lead to a loss of information, low output quality, or even a break down of the whole process. Slow or monotonous SL input makes interpreters store often useless information for unnecessarily long periods of time, putting a superfluous strain on memory and filtering capacities, and forcing 
them to adapt their natural output rate and pace to the halting speech of the talker. Furthermore there is the danger of a lapse of attention on the interpreter's side.

In accordance with other researchers and interpreters Gerver (1969) estimated an input rate of ninety-five to a hundred and twenty words per minute to be the ideal range in order to provide a constant quality of interpretation. In experiments carried out to that effect, the input rate is usually measured against variables such as number of self-corrections, omissions, omissions, 'correctness' of the translation, or quantity of important information retained.

Density. redundancy and other idiosyncrasies of the input

Much of how 'translatable' a text is depends on its density, the degree of redundancy, and other individual and categorical characteristics such as the amount of proper names and figures employed, or the degree to which a very specialized vocabulary is used.

A particularly dense text can either contain a large amount of important information or many so-called fillers and circumscriptions, which make it less penetrable in terms of the number of words uttered rather than the informative content concerned. If a lot of new information is contained in the original message, the interpreter has to allot much processing capacity to the analysis and synthesis of this message in the two languages involved. Alternatively strategies to condense the information into 
its gist can be applied to economize the total time and energy available for processing. In both cases the more interpreters know about the subject, and the more extensive their general knowledge, the easier the processing of dense information. Often the additional knowledge available can be used in a top-down manner to make sense of the message and to transform it into the target language equivalent. As far as messages which show a high percentage of noninformative fillers, etc. are concerned, the difficulty is to filter out necessary and relevant information at an early stage in order not to waste any processing capacity.

The consideration of different types of redundancy can also help to shed some light on the 'interpretability' of individual SL texts. Systemic and textual redundancy (Alexieva 1992), i.e., redundancy due to the characteristics of a specific language system and the particular structure and content of a text in the form of semantic repetitions for example, will help the interpreter to process information as they are likely to trigger the before mentioned 'short-cut', avoiding all steps up to the activation of the TL elements. Systemic and textual redundancy will also contribute considerably to the prediction mechanism, cutting down on the processing capacity for the part of speech in question and making more capacity available for other tasks.

Objective and subjective redundancy (Alexieva 1992) across several texts or speeches, i.e., the reoccurrence of a certain set of vocabulary or structures typical of a specific text type, helps to increase an interpreter's knowledge of a domain or subject. In return 
the interpreter will be able to establish a reliable prediction mechanism and strategies that allow for the efficient use of the knowledge gained in a top-down manner, complementing and enhancing the bottom-up processes employed in analysis and synthesis.

In addition to the two types of redundancy already mentioned, a third type is of special significance in interpretation: semantic and semiotic redundancy (Alexieva 1992). As in any other face-toface communication the linguistic signs of the spoken message are accompanied by semiotic signs such as gestures, graphic displays, slides, etc.. If linguistic and non-linguistic signs are in agreement with each other, the interpreter's work is facilitated, as the signs will confirm each other and contribute to the analysis of the message. The non-linguistic elements can also, to a certain degree, make up for information that has been lost or only partially understood during the listening process, thus preventing a possible breakdown, and reinforce the linguistic information in a way that positively influences the prediction mechanism. However, if the linguistic and non-linguistic information provided do not correspond, the interpreter's ability to decode the SL message will be impaired due to more than one possibility of interpreting the signs. The interpreter will consequently have to spend more time and energy processing and considering the alternatives, and will have to rely more heavily on less 'secure' skills, such as creativity, to restore the original message. In addition the valuable prediction mechanism 
will also be impaired by the variety of contradictory clues provided by the overall input.

Even if the interpreter knows the subject domain well, and if the situation of interpreting under stressful conditions has become part of the professional routine, there are circumstances under which even experienced interpreters are likely to be challenged.

One of these 'stumbling blocks' is the occurrence of technical terms, proper names, and numbers. Although they cannot be avoided-and they are in fact very frequent in economical, political, and technical speeches--they are known to constitute major difficulties for interpreters. What makes them particularly hard to process is the fact that they are very short and therefore "particulièrement vulnerable à la distorsion du son . . . , au bruit . . . et au relachement de l'attention de l'interprète." (Gile 1985, 200) [particularly vulnerable to distortions of sound, to noise, and to lapses of attention of the interpreter] (my translation) In other words, their informational content is specific and important, but bears (in the case of numbers or proper names) no direct relation to the semantic message of the text itself, or (in the case of technical terms) carries a very complex and specific meaning that is often difficult to grasp and paraphrase in its complexity. The processing of numbers and proper names can only be 'facilitated' by close listening--the overall listening conditions in the conference room as well as the technical equipment being of prime importance--and focused attention. The ease of analyzing and synthesizing technical terms is to a certain degree subject to the interpreter's practical experience, 
linguistic and domain-specific knowledge, and the effort put into conference preparation. If documentation is available for a conference, which is unfortunately rarely the case, interpreters are strongly advised to read and prepare this documentation beforehand. The annotation of the documentation and the regrouping of terms in chronological order of appearance or into conceptual categories will help the interpreter to know what to expect and will also speed up the analysis and synthesis of the input. A read-along while listening to the speech is not recommended, as reading puts an additional strain on perception and language processing mechanisms. Digressions from the written documentation will also cause confusion and subsequently a slowing down of the interpretation process, or possibly a break-down, if the interpreter can not quickly overcome confusion and information loss. In cases where documentation is not provided, the interpreter can nevertheless try to prepare himself by reading up on the subject, doing terminological research to update domain-specific and linguistic knowledge, thus cutting down on the effort that has to be expected to be made when unknown or 'dormant' phrases and expressions are encountered in the process of interpreting. Gile (1985) suggests that the difficulties that are observed during the processing of technical terms, proper names, and numbers, can also be partly overcome by the presence of a 'passive' colleague in the booth, who concentrates on listening and the retrieval of special terms, e.g., by using a dictionary. It would seem ,however, that the presence of another professional has an 
intimidating effect on many interpreters, makes them nervous, and increases the risk of confusion and lapses of attention.

Another complicating factor found especially during the first stages of input processing, are accents or dialects. Considering the fact that the source language is usually not the interpreter's mother tongue or active language, it can be assumed that a 'distortion' of the input by a foreign accent or local dialect makes the analysis of what is being said and heard even harder. The interpreter who is not used to the linguistic variety presented will have to sacrifice much processing capacity to the initial phases of processing. Prior knowledge of the speaker's mother tongue or familiarity with the idiosyncrasies of a dialect can help the interpreter to be prepared for and more easily recognize and cope with sounds, words, and expressions that one would not normally expect to hear in a standard version of a particular language. An interpreter who knows for example that the speaker delivering a speech in English is French will expect deviations from the standard pronunciation and is likely to recognize the intended word or expression more quickly, despite a misplaced stress, a mispronounced vowel, or a literally translated construction from the French.

Not only accents and dialects, but also the lack of clarity or loudness can make the decoding of the input difficult for the interpreter. While a loud and clear speaker can significantly facilitate the first stages of processing, low volume or mumbling force the interpreter to put significant effort into initial processing, thus decreasing the possibility of predicting what is to 
come at an early stage. If the acoustic quality of the input is too poor to allow for continuous, or at least partial processing, information will be lost to a degree that can entail the break-down of the entire process.

Closely connected to the quality of the input itself are the overall listening conditions in the interpreter booth and the conference room. Lederer (1981) observed that "parmi les bruits qui nous arrivent, nous choisissons ceux dont nous faisons des sons significatifs et laissons à l'état de bruit ceux qui ne nous interessent pas." (Lederer 1981, 59) [Among the noises that reach our ear we chose those that we regard as significant and regard as mere noise those that do not interest us] (my translation) Yet, in a setting where background noises mask and distort the sound of the speaker's voice, the interpreter is hard put to filter out the significant sounds that implicitly carry the information to be processed. Whatever the source of a background noise--be it the audience, the acoustic layout of the conference room, the voices of other interpreters or speakers, poor electronic equipment, badly isolated booths--the highly demanding task of listening and speaking simultaneously and processing information quickly from one language to another is made even more difficult by poor listening conditions. The initial processing stages are more difficult, and more top-down processing will be necessary later on to restore missing information. Similarly, the chances of prediction are clearly reduced, if the input provides only parts of the information to be interpreted. 


\section{Input chunking and initial processing}

Although an important process in simultaneous interpretation, as it provides the segments to be analyzed and synthesized in the target language, the issue of input chunking is still a matter of controversy. Opinions as well as experimental findings concerning the subject differ widely. Some researchers concur with Barik (1969) and believe that pauses in the original speech are used to segment the input or do at least assist segmentation, decoding and encoding of the SL message (Gerver 1971). Goldmann-Eisler (1972) found grammatical and lexical aspects of the languages involved to be the main factor, along with a so-called subjective organization (Goldman-Eisler 1972, 127). The result of this organization is, according to Goldman (1972), that the interpreter has three basic possibilities to chunk input: identity, where the encoded chunk is identical with the SL chunk, fission, indicating that the interpreter starts encoding before the end of an input chunk is reached by the speaker, and fusion, referring to the storage of one or more input chunks before the interpretation is started. This view allows for the possibility that pauses can delineate units of meaning, but also accounts for the fact that segments of the stimulus do not necessarily have to be divided by markers such as pauses.

Hamers and Blanc (1989) agree with Goldmann-Eisler's view and stress that input chunking, as an active part of language processing in $\mathrm{SI}$, is a function of the languages involved, i.e., that structure is indeed a determining factor in interpretation. 
Lederer (1981), on the other hand, does not believe that theoretical experiments to determine the length of chunks or the time interpreters spend listening to the input before starting the encoding are valid (as they assume that $S I$ is a pure process of transcoding words or structures). Furthermore, she does not subscribe to the view that input chunking is a function of the languages involved. Her view is also in contradiction with Moser's (1978) interpretation of input chunking in terms of Fillmore's (1968) case grammar as introduced in the preceding chapter. Although the argument, that verb-late languages provide parts of the information at a later point in time than others, can not be dismissed, this fact can not be viewed as the all-determining factor for the interpretation of information, as interpretation has to be regarded (and has been described as such in this paper) as a process that leads to the rendering of equivalent ideas rather than equivalent words or structures. Moreover, the claim that interpretation from German for example, should be more 'difficult', or that the interpreter will have to wait longer to be able to start decoding and encoding when translating from German into English than in the case of an English-German interpretation, loses its validity when we consider that native German speakers can understand the meaning of a sentence in their mother tongue just as fast as an English person will understand the same sentence uttered in English. It is highly unlikely to observe "un auditeur allemand rester huit, dix secondes le visage hébété jusqu' à ce qu' enfin le verbe lui apport la lumière." (Lederer 1981) [a German listener 
waiting for eight or ten seconds with a dazed expression until the verb finally enlightens him] (my translation) Furthermore there is no evidence that predictions are rarer or made more slowly when interpreting from the German.

Willet (1974) too advocates the view that language does not matter to the speed or way of input chunking and information processing. In his opinion the theory that languages with similar structures (as e.g., French/Italian) are 'easy' to interpret, while interpretation between languages with very different structures (e.g., German/ Spanish) are more laborious, has to be dismissed, as it rests on the the false assumption that "Dolmetschen vorwiegend Umkodierung sei, dass heisst, dass in erster Linie Sprache umgesetzt, nicht Inhalt neu formuliert werde." (Willet 1974, 97) [simultaneous interpretation means mainly transcoding, i.e., that primarily words are being transformed and not content reformulated] (my translation)

As far as the length of the units to be encoded or the time the interpreter waits before starting to interpret is concerned, assumptions and findings vary between a delay of two to three seconds (Gerver 1971; Lederer 1981) and chunks of four to five words (Goldmann-Eisler 1972). Lederer (1981) argues that neither the number of words nor the length of time that passes before the interpreter starts uttering an interpretation are an ideal measurement, as there is no one-to-one relationship between the number of words expressing the same idea in two different languages, and because the time of delay depends too much on 
individual circumstances and characteristics of a particular text or speaker.

On the whole it seems that the ease of interpreting from one language into another, the way in which interpreters chunk the SL input, and the time lapse between the speaker output and the start of the interpreter's corresponding output are a function of the relative difficulty of the text, its density, the degree of redundancy, and the quality of transmission. Furthermore the interpreter's individual linguistic competence in the languages involved, individual practise and expertise as an interpreter and domainspecific and general knowledge are importamt factors determining the interpretability of a text. The interpreter has also to be able to focus attention, manage processing capacity, and recognize the gist of information in what is said. Finally the ease of interpreting will depend on the criteria the individual interpreter has for the quality of interpretation, the time pressure, and the cultural and semantic differences that divide languages from each other, rather than on the occurrence and amount of speaker pauses, preset 'chunking-rules', or structural differences of the languages involved.

As the SL input is the basic element of SI, i.e., its raison d'être, providing the message (the 'bottom') that has to be transformed into another language in order to be made understandable to the actual listener, it is certainly a determining factor for the information process, but other factors also play a significant role in assuring a smooth and efficient interpretation. 
Syntactic and semantic processing

As has been shown in the theoretical part of this paper, human information processing depends not only on the original input and stimulus-driven processes, but also on top-down processing, the organization and accessibility of long-term memory (LTM), and the availability of sufficient short-term memory (STM) space at the GAM (Generated Abstract Memory) stage. Once the perceptual units have been stored in SAM (Synthesized Auditory Memory), the understanding of meaning depends on "finding the best match between the perceptual information in SAM and the lexicon in longterm memory." (Massaro 1978, 307) The successful interpreter therefore has to have the best possible competence of the source language (in terms of grammar, vocabulary, etc.) to ensure that language-specific knowledge can be used to 'interpret' and, if necessary, complement the information provided by the stimulus itself. Interpreters also need to know as much as possible about the specific domain they work in and about the world in general. Only if these prerequisites are fulfilled can the interpreter efficiently and integratively use the two sources of information: the stimulus and the syntactic and semantic context in which it is represented.

As GAM is limited in its capacity, but crucial to the shortterm storage of information, a swift pace of further processing will help to 'clear' the short-term storage, so that subsequent information can be held.

Top-down processing at these stages is of great importance, especially if the original input is distorted or fragmentary. A word 
that has not been perceived in its entirety or has been missed altogether can be 'guessed' from the immediate context or deduced. Similarly, a word that is not recognized can be made available for further processing by the interpreter's ability to infer its meaning from the grammatical structure to be expected in a given phrase or sentence, or by using deductive reasoning to understand the meaning of what has been said.

As the notion of concepts has already been discussed in the previous chapter, suffice it to say here that the more interpreters know the more efficient will they be in terms of activating the appropriate conceptual base and the relations between concepts and the SL and TL nodes attached to them. Only then will the bottom-up stimulation of the conceptual base and top-down processes that enhance the stimulus be able to work together integratively and lead quickly to the aim of actually 'understanding' the meaning of the original message, however fragmentary or linguistically difficult to grasp and process it may have been up to this point. It is also at this point that the time and effort-saving prediction mechanism can be initiated on the basis of preceding context and concept-driven mechanisms. This, as well as rapid processing at previous stages, can be a good means for the interpreter to manage the limited processing capacity available in a highly efficient way. In other words, if the interpreter is able to use overall knowledge and what has been understood before to draw immediate conclusions on the contents of the input to come, these top-down mechanisms provide a valuable short-cut of the usual interpretation process and leave 
processing capacity available for other, possibly more difficult stages. It should therefore be the aim of SI training, and of any practising interpreter for that matter, to enlarge and optimize the scope of knowledge, to improve the speed and integrative use of topdown and bottom-up processing, and to try to establish and reinforce a maximum of concepts, relations among them and to $S L$ and $T L$ elements.

\section{SYNTHESIS, OUTPUT AND EVALUATION}

\section{Synthesis and target language output}

As has been shown with the previously presented model, the activation of TL units is assumed to be a function of the activation of concepts. Nevertheless, the final choice of TL elements is not a mere question of bottom-up processing, i.e., dependent on the previous stage of processing, but depends heavily on top-down processes that are influenced by the interpreter's knowledge and creativity. As a variety of concepts and TL elements are possibly activated, it is the interpreter's task and choice to pick the most appropriate one, according to individual linguistic abilities, personal criteria, and the processing capacity available at this point in time. It is the interpreter's task to "mobiliser une expression qui soit plus consciemment fonction du sens et non de l'autre langue." (Lederer 1981) [call up an expression that is more consciously a function of the sense than of the other language] (my translation) In concentrating on the sense of the original message and the fact that 
the TL should phonetically, morphologically, semantically, and syntactically speaking be the main generator of the output, the interpreter should be able to avoid to let the structure and wording of the original 'smell through'. The more or less conscious effort to formulate the TL output in a way structurally as different as possible from the original will help to prevent one of the most common flaws of many interpretations: interference.

Interference can occur at all levels of linguistic processing, but Lederer (1981) identifies morphological adaptations ${ }^{3}$, incorrect gender agreement of adjectives, pronouns and nouns ${ }^{4}$, and literal translations of pronouns, e.g., in locatives. As the TL is typically the interpreter's mother tongue these instances of interference are usually not due to a lack of linguistic knowledge. They can partly be explained as the consequence of the storage and presence of the original message, the memory of which has not yet faded and influences the synthesis and production of the TL output. Other reasons for interference are often due to the quite different ways in which linguistic phenomena (such as animacy and relative clauses) manifest themselves in the structure of different languages. These often very subtle differences usually go unnoticed in 'normal' bilinguals, but can pose difficulties in an interpretation, which demands total independence from the SL wording and structures, and

3 An example of morphological adaptation would be the translation of 'political responsibility' as ' responsabilitē political instead of responsabilité politique in French

4 The translation of the German phrase die schnellste Bahn. mit der... (feminine adjective, noun and relative pronoun) into French as * Le train le plus vite laquelle.... (masculine noun and adjective, and incorrect feminine relative pronoun) would be an example of this kind of interference. 
the focusing on the idea or sense of the original message and its expression in the TL according to the latter's own independent formal and semantic rules.

The interpretation of culturally unrelated languages may create additional difficulties which can hardly be overcome by pure linguistic knowledge. These difficulties can be due to a lack of overlap or connection between concepts. An SL node attached to a concept characterized by certain features and relations between them may not have a complementary TL node, or may only have a corresponding $T L$ node that covers only parts of the meaning conveyed by the SL term. To cite a well-known example: terms signifying different kinds of snow in Eskimo languages have no corresponding equivalents in European languages, and have to be generalized or circumscribed in those. The English word 'bone', on the other hand, will have to be translated by different words in German, depending on whether it refers to humans and mammals (Knochen) or fish (Graete). An experienced and efficient interpreter will not only know about these discrepancies, but will also develop strategies to deal with similar situations quickly and to activate the appropriate TL term or paraphrase without losing too much processing capacity. Here again top-down processing based on linguistic, domain-specific, contextual and general knowledge is of primary importance for the generation of the appropriate TL output and for the prediction mechanism. The retrieval of 'difficult' or semantically not totally equivalent $T L$ nodes is also facilitated by training and frequent use, so that the experienced interpreter will 
have less difficulty finding an appropriate TL equivalent, even if the cultures of the two languages involved have little in common in terms of concepts.

When synthesizing the TL paraphrase and generating the output the interpreter makes use of various tactics that determine the output and are in turn dependent on personal parameters and circumstantial factors. They guide and enhance the top-down processes involved in rendering information as immediately and close to the original as possible, while ideally avoiding interference and costing a minimum of effort.

While simplification, i.e., the replacement of the original idea by a more global, less detailed one (Gile 1985), will need little time and effort but may entail the loss of details, explanations or paraphrases may be more efficient to convey the original idea but cost time and processing capacity. Omissions, be it by accident or as a consciously chosen tactic, usually mean a loss of information and can occur as a result of a lack of memory space or difficult input processing that leaves the interpreter with insufficient processing capacity during synthesis and output. They can also be used on purpose as part of the interpreter's creative process in order to save time and effort and to be able to concentrate on more demanding parts of the interpreting process. Additions, on the other hand, especially empty phrases, are often used to prolong the output and to win time for more or more relevant information to come in and complement the information received and processed so far. Other than the other tactics additions are not triggered by previously 
provided input information but rather the lack of it. They have to be evoked by the interpreter in the appropriate situation as additional, self-generated output similar to the empty phrases that are used in normal conversations to 'think about' what we are saying or to give the other speaker time to provide us with some more information.

Although interference is on the one hand one of the dangers and flaws of interpretation it is on the other hand to some degree used as a tactic. Neutralization refers to the morphological or phonological modification of the SL term (Gile 1985) and can be an effective means of saving time and effort if the two languages involved are closely related and SL terms are regularly and frequently used in the $T L$, or if the listeners are used to similar bilingual conferences or have at least a basic knowledge of the SL. Similarly adaptations, i.e., phonological neutralizations (Gile 1985), are applied if the correct TL term cannot be retrieved in time, or if the SL and TL terms are very much alike. Although the danger of masking or rendering the target term incomprehensible is greater than with neutralizations, adaptations are little time consuming and may be worthwhile to be attempted in order to prevent a loss of information or a break-down of the whole process. So-called compilations refer to the use of the same term with very similar pronunciation in both languages (Gile 1985) and are an effective and frequently applied tactic in the technical and computer domain, as newly created terms in these fields often progress in parallel across languages and almost provide a lingua franca vocabulary. 
Once the TL output has been generated, the interpreter, possibly after monitoring or amending the result of the synthesis if time and processing capacity allow it, has to utter his message. At this point linguistic ability can be used to enhance, emphasize and modulate the output through prosody, semiotics, and the speed, clearness, and loudness of speaking. If time has to be made up for, the interpreter can speed up the output rate. In cases where parts of the original information have been lost and the TL output risks to be incoherent or stocking, the interpreter can make up for these drawbacks by a firm voice and fluent output, if only to keep up appearances or to regain confidence and calm.

A final important instance of the interpreter's output is the occurrence of self-corrections. These are a function of selfmonitoring once the TL message has been uttered and are due either to the interpreter's recognition of a semantic, syntactic, morphological, or phonetical error in the synthesis process of the chunk in question, or can be an amendment of an apparently correct interpretation, if the subsequent context sheds a new light on and changes the meaning of what has been said and understood up to that point. Thus self-corrections can be a powerful means of explaining and understanding the mechanisms involved in the storage and retrieval of information in simultaneous interpretation.

\section{Evaluation of SI}

A topic that has been treated only marginally in research and literature, although it seems to be quite important for a 
comprehensive picture of simultaneous interpretation, is the evaluation of the outcome of information processing in SI. This lack of investigations can to a certain extent be explained by the fact that the factors influencing the interpretation process are so variable and depend on so much more than the interpreter's skills and abilities. It can be said, that a qualitatively good interpretation does not necessarily reflect the expertise of the interpreter, but can at least partly be the result of ideal circumstances, such as good acoustics, a comfortable speed of input. On the other hand a poor interpretation may well be the outcome of an accumulation of adverse conditions against which even the most knowledgeable, specialized and experienced interpreter is powerless. For the same reasons an evaluation of the quality of interpretation through an assessment of what the actual listeners have understood correlated to the information content of the SL input seems hardly promising in terms of validity.

A recently proposed "CREDIT" model (Hu 1991) suggests the systematic evaluation of interpretation on the basis of a five-scale and a hundred-point system in which six aspects (Credibility, Respectability, Elegance, Diversity, Immediateness, Technicality) of interpretation are evaluated by an on-site committee. This evaluation is complemented by an analysis of the recorded interpretation, back-interpreting, designed experiments, and knowledge testing by an off-site committee. The validity of such an evaluation is questionable though, as the six aspects in question are not necessarily or exclusively the main factors to have a 
determination influence on interpretation (Hu 1991). Furthermore an evaluation by colleagues or other $S I$ experts is as much subject to personal bias as is any language performance assessment in schools, universities, or other test situations. Nevertheless, the opinion of experienced interpreters and specialists in the domain of SI seems to be the only feasible form of evaluation that can be offered to assess the quality of the outcome of information processing in SI.

\section{THE TRAINING OF SIMULTANEOUS INTERPRETERS}

The proposed model of information processing in simultaneous interpretation fits the competence and performance of experienced professional interpreters. It can nevertheless be useful to determine and describe the skills and abilities which to train and improve any training programme for simultaneous interpreters should aim at. Considering the human processing abilities and the individual skills involved in SI, the focus of SI training should be set out to enhance and improve linguistic abilities, the ability to do two things simultaneously, short term memory (STM) and long term memory (LTM) and the skill of rapidly abstracting the principle ideas from an often complex message, and transforming it into an equivalent message in a different linguistic code. In other words, future interpreters should be prepared to effectively carry out a complex high-skill information processing activity composed of various subskills and involving listening, understanding, producing, and uttering a message in two different codes. 
Although a possibly perfect performance and competence of the two languages involved is necessarily part of SI training--a near perfect command of two languages is indeed a prerequisite for admission to some SI courses--language exercises to ensure an optimum language-specific knowledge and performance in the source and target language are anchored in most curriculums of interpreter schools, but cannot be considered in detail within the framework of this thesis. Similarly culture learning or special terminology courses that develop the understanding of culture-specific issues and domain-specific knowledge can not be considered in this thesis.

The focus of this chapter will be on exercises training the cognitive and language-independent performance of interpreters as well as SI-specific skills. Some consideration shall also be given to the question whether translators and simultaneous interpreters should receive the same kind of training, or whether they should be trained differently, and if so at what level.

For more or less all SI exercises that will be presented subsequently from the more simple and basic to the more complex and specific ones, teachers and researchers recommend that they should be practised first in the mother tongue, then in the source language. Only at an advanced stage should both languages be used at the same time, and the difficulty of the material be increased gradually. This reflects the view that the major difficulty in SI is not only the simultaneous use of two different languages, but also the special skills and processes on which this task calls. In order to ensure that the meaning of the issues presented in the exercises is 
really understood, instructors are advised to ask questions concerning the contents of the texts or speeches used after each exercise. Thus control over semantic processing is said to be ensured to a certain degree.

In order to train the SI students' STM capacity and to teach them to grasp the informational structure and the main ideas of a spoken message, simple listening exercises, followed by immediate reporting back of what has been understood, are used. A more advanced and difficult version of this exercise is listening combined with an immediately following key word report, resume, or synthesis in the form of an abstraction of the ideas presented previously, the speed of presentation being increased by-the-by. The aim of these exercises is to train the ability to grasp the gist of ideas, to eliminate superfluous information or structures, to use a certain degree of creativity, and to slowly help the students to find their own pace of listening and speaking.

The close paraphrasing of the meaning of texts with decreasing redundancy and increasing speed is regarded as an exercise that closely approaches SI. It is based on the idea that the TL message can be described as a paraphrase of the SL message in an other language. It can be applied to improve the ability to understand the main ideas of a message and the associational fluency that is crucial for the activation of concepts.

Very popular with some instructors and much disputed by others, so-called shadowing is used in many $\mathrm{SI}$ training institutions. It has been described as 
. . a paced, auditory tracking task which involves the immediate vocalization of aurally presented stimuli, i.e., word-for-word repetition in the same language, parrotstyle, of a message presented through headphones. (Lambert 1988, 381)

Proponents of this task argue that it can be used to explore and improve the limits of listening and memory capacity, to practise listening and speaking simultaneously, to learn how to divide attention and, if it is practised under noisy conditions to introduce the trainees to the real interpretation situation under adverse listening conditions. Opponents, on the other hand, believe shadowing to be restricted to the act of conveying mere words instead of encouraging the understanding of meaning. They believe it is purely mechanical and reinforces the tendency to stick too closely to the original input.

Related to shadowing exercises is the so-called dual-task training, usually involving listening to a recorded passage as one task, and a second, more 'mechanical' task, as such counting backwards. The underlying idea of this exercise is that two different kinds of information can be processed in parallel, if they do not call on the same mechanism and allow for one of the tasks to be automatized, preferably at a pre-attentive level. Although dual-task exercises are not very natural and put a great strain on normal human processing abilities, they prepare the trainees for 
simultaneous processing and can be useful for improving the skill of dividing attention.

A whole range of anticipation tasks is assumed to enhance anticipation as the "basis of varying indicators encountered during decisions in simultaneous interpretation," (Kalina 1992, 255) and to reinforce the students' awareness of top-down and bottom-up processes. Read-aloud exercises or shadowing of spoken texts with semantic gaps, that have to be filled in by the students, aim at demonstrating top-down processes by encouraging the students to make use of their knowledge as well as the preceding context. Cloze exercises are widely believed to be a valid measure of evaluating not only concept-driven processing, but also the general lexical, syntactic, and semantic aspects of language processing, and the ability to use stimulus-driven processing skills to complete a fragmentary input. In addition to ensuring linguistic competence, anticipation tasks also test general and domain-specific knowledge and can be employed to assess a trainee's ability to make rapid and creative decisions. A further variant, productive anticipation tasks containing unexpected turns, teaches the students how to quickly and efficiently correct and amend their output. In so-called probabilistic prognosis exercises, where the students are asked to prepare themselves, e.g., by reading some information on a certain subject, and then have to complete fragmentary statements as quickly as possible. The answer should be compatible with the informational contents of the texts and the subject reality of the topic. This task is employed to make the students get used to the 
real conference situation, which ideally includes preparation, and to speed up reaction time. Moreover this kind of exercise trains the ability to use top-down and bottom-up processes integratively.

In order to prepare the students for the difficult adverse conditions such as temporal restrictions, stress, or bad listening conditions discourse processing in adverse practice conditions is part of almost every SI training curriculum. Exercises in that category range from sight translation, answering questions in a booth with open microphone while listening to the next question to shadowing under noisy conditions and cloze exercises with spoken texts of poor acoustic quality.

Another question to be considered in the framework of SI training is whether, and if so to what degree, it should be different from the training undergone by translators. As has been mentioned earlier in this work, translation and simultaneous interpretation do share a number of characteristics as well as the aim to reformulate a message in one language in another language while conserving the main ideas of the original message and ideally its style and contextual relevance. Yet, the description of $S I$ in terms of information processing and the conclusions that can be drawn from that approach for practical SI should have made it clear, that SI involves crucial skills that go beyond those characterizing the translation of written texts. The space and time constraints in SI as well as the very limited access to additional information sources demand a great degree of flexibility, versatility, rapid decision making, and efficient crisis management as a function of the limited 
processing capacity available and a most efficient integration of top-down and bottom-up processes. As all these abilities can also come in useful in translation, but can hardly be expected to occur naturally or to be acquired by self-instruction, there seems to be good reason to advocate training programmes on the basis of a socalled two-tiers system (Renfer 1992) as applied in Geneva and Zurich schools for translators and interpreters, or a postgraduate interpreter training subsequent to the successful completion of a translator's degree (as implemented in many prestigious schools and the training programmes of multiple international organizations). These programmes involve consecutive stages of translation and interpretation. They have the advantage of first equipping the students with a thorough training in text analysis, written expression, grammar, and background lectures, all emphasizing the awareness of communicative processes and the importance of background knowledge and cultural education. The translator training is thus subsequently used as a basis for specialized SI training, giving the SI trainee the possibility to concentrate on more 'technical' aspects and developing the flexibility and expertise required in $\mathrm{SI}$. 


\section{CHAPTER VI}

\section{CONCLUSION}

As "no model ever solves all the problem it defines and no two models leave all the same questions unsolved" (Moser 1978, 353), the attempt to model the process of simultaneous interpretation from an information processing point of view may be regarded as a contribution to the goal of understanding $S I$ as a unique example of human information processing and of describing it in a comprehensive and interdisciplinary way.

It has been shown that $\mathrm{SI}$ involves a flow of information from a source language input to the output of an equivalent target language message via language-independent semantic representations. During the various steps of the interpretation process bottom-up mechanisms, that use the output of the respective preceding stage as an input or stimulus for further processing are applied. These are complemented by top-down mechanisms, which complete, enhance or even substitute and override the stimulus by using information encoded in memory. Both mechanisms are integrated to decode, understand and encode information simultaneously in two languages.

Models comprising stages and mechanisms like those described can be a powerful tool not only to define precisely how information 
in $\mathrm{SI}$ is processed and understood to produce a message in a target language equivalent to that conveyed in the source language, but also to explain how the interpreter can manage to cope with two linguistic and cognitive demanding tasks, i.e., listening and speaking in two languages, simultaneously.

By assessing the various tasks and processes involved in SI, and thus describing the actual working methods of interpreters, the progress of the debate concerning the selection and education of simultaneous interpreters on all levels can be furthered and encouraged. The information processing model has been applied to the development of SI training and the understanding of practical SI in this paper, and demonstrates the implications that models and theoretical research in cognitive issues such as attention, processing capacity, processing mechanisms, memory, knowledge representation, and expertise, can have for practising interpreters and the development of SI training.

Despite the fact that an information processing point of view is a powerful means of illuminating the skills and processes underlying SI, and of developing teaching models independent of the languages involved, this thesis cannot describe all aspects of $\mathrm{SI}$ exhaustively. Among the domains and subjects not explored in detail are the exact description of acoustic issues, the automatization of sub-skills, and the explanation of discourse processing and of learning as a crucial mechanism within the information process.

Other topics of further research within the given context are to be found in the areas of cognitive science and neurolinguistics. 
An investigation of the importance and nature of lateralization of bilinguals in general and simultaneous interpreters in particular could yield interesting insights into the foundations of bilingual processing. Research in Machine Translation and Artificial Intelligence might possibly be combined to shed some light on human information processing, while the description of $\mathrm{SI}$ as an example of the latter can possibly be seen as a first step to examine the possibilities of modelling the interpretation process, or at least parts of it, computationally.

To really understand the process of simultaneous interpretation with all its complex skills and mechanisms, the cooperation of a wide range of disciplines is still needed. Professional interpreters and researchers from various domains, including all areas of linguistics, didactics, cognitive psychology and Artificial Intelligence, have to work together to contribute to a comprehensive overall picture of this intriguing field. The combination of stimulus- and knowledge-driven, bilingual information processing that involves the rare occurrence of simultaneous listening and speaking in one 'system', the interpreter, cuts across many domains. In other words,

... it seems high time that we freed ourselves from the shackles of any single discipline, be it linguistics or language pedagogy, and we started to work on a didactic specific to interpreting/translating which is based on a theoretical framework which by definition needs to draw on these and many more areas of study and research. (Gentile 1991, 350) 


\section{REFERENCES}

Alexieva, B. (1990) Creativity in simultaneous interpretation. In Babel, 36 (1), 1-6.

Andersen, R. B. W. (1976) Perspectives on the role of interpreter. In R. W. Brislin (ed.) Iranslation: Application and Research. New York: Gardner.

Andersen, R. B. W. (1981) Two perspectives on pidginization as second language acquisition. In R. W. Andersen (ed.) New Dimensions in Second Language Acquisition Research. Rowley, Mass.: Newbury House.

Anderson, R. C. (1985) Cognitive Psychology and Its Implications. New York: W. H. Freeman.

Baddeley, A. D. (1992) Working memory. In Science, 255, 556-559.

Baddeley, A. C. and Hitch, G. (1993) The recency effect: implicit learning with explicit retrieval? In Memory \& Cognition, 21 (2), $146-155$.

Barik, H. C. (1969) A study of simultaneous interpretation. Unpublished Ph.D. thesis. University of North Carolina.

Barik, H. C. (1971) A description of various types of omissions, additions, and errors encountered in simultaneous interpretation. In Meta, 16, 199-210.

Barik, H. A. (1973) Simultaneous interpretation: temporal and quantitative data. In Language and Speech, 16, 237-270.

Bell, R. T. (1993) Iranslation and Translating. London: Longman.

Ben-Zeev, S. (1977) Mechanisms by which childhood bilingualism affects understanding of language and cognitive structures. In 
P.A. Hornby (ed.) Bilingualism: Psychological. Social and Educational Implications. New York: Academic Press.

Berg, Th. and Schade, U. (1992) The role of inhibition in a spreadingactivation model of language production. In Journal of Psycholinguistic Research, 2 (6), 405-35.

Bialstock, E. (ed.) (1992) Lanquage Processing in Bilingual Children. New York: Cambridge University Press.

Brower, R. A. (ed.) (1966) On Translation. Cambridge: Harvard University Press.

Butler, C. S. (ed.) (1992) Computers and Written Texts. Oxford: Basil Blackwell.

Carroll, F. W. (1978) Cerebral lateralization and adult second language learning. Unpublished Ph.D. dissertation. Albuquerque: University of Mexico.

Chernov, G. V. (1969) Linguistic problems in the compression of speech in simultaneous interpretation. In Tetradi Perevodchika, 6, 52-65.

Cohen, G., Eysenck, M. W., and LeVoi, M. E. (1986) Memory. A Cognitive Approach. Milton Keynes, England: Open University Press.

Comrie, B. (1989) Language Universals and Linguistic Typology. Oxford: Basil Blackwell.

Cowan, N. (1993) Activation, attention, and short-term memory. In Memory and Cognition, 21 (2), 162-167.

Crowder, R. G. (1993) Short-term memory: where do we stand? In Memory and Cognition, 21 (2), 142-145.

Darò, V. (1992) Neuropsychologie und neurolinguisische Aspekte des Simultandolmetschprocesses. In Babel, 38, 1-9.

DeBot, K. (1992) A bilingual production model: Levelt's "speaking" model adapted. In Applied Linguistics, 13 (1), 1-24. 
di Vesta, F.J. and Gray, G. S. (1972). Listening and note-taking. In Journal of Educational Psychology, 63, 8-14.

Dollerup, C. and Loddegaard, A. (eds.) Teaching Translation and Interoretation. Amsterdam: J. Benjamins.

Ericsson, K. A. and Polson, P. G. (1988) A cognitive analysis of exceptional memory for restaurant orders. In M. T. H. Chi, R. Glaser and M. J. Farr (eds.) The Nature of Expertise. Hillsdale, NJ: L. Erlbaum Associates.

Fillmore, C. J. (1968) The case for case. In E. Bach and T. Harms (eds.) Universals in Linquistic Theory. New York: Holt, Rinehart and Winston.

Garcia-Landa, M. (1985) L'oralité de la traduction orale. In Meta, 30 (1), 30-36.

Gathercole, S. E. and Baddeley, A. D. (1993) Working Memory and Language. Hove: L. Erlbaum Associates.

Genesee, F., Hamers, J. F., Lambert, W. E., Mononen, L., Seitz, M. and Starck, R. (1978) Language processing in bilinguals. In Brain and Language, 5, 1-12.

Gentile, A. (1991) The application of theoretical constructs from a number of disciplines for the development of a methodology of teaching in interpreting and translating. In Meta, 36 (2/3), 34451.

Gerver, D. (1969) The effects of source language presentation rate on the performance of simultaneous conference interpreters. In E. Foulke (ed.) Proceedinas of the 2nd Louisville Conference on Rate and/or Frequency Controlled Speech. University of Louisville, 162-184.

Gerver, D. (1971) Simultaneous interpretation and human information processing. Unpublished Ph.D. dissertation. Oxford: Oxford University. 
Gerver, D. (1972a) Simultaneous interpretation and human information processing. London: Social Science Research Council Research Report, HR 566/1.

Gerver, D. (1972b) ASPA- Automatic Speech-Pause-Analyser. In Behavioural Research Methods And Instrumentation, 4, 265-270.

Gerver, D. (1974) The effects of noise on the performance of simultaneous interpretation: accuracy of performance. In Acta Psychologica, 38, 159-167.

Gerver, D. (1976) Empirical studies of simultaneous interpretation. In R.W. Brislin (ed.) Translation: Application and Research. New York: Gardner.

Gerver, D. and Sinaiko, H. W. (eds.) (1978) Lanquage. Interpretation and Communication. New York: Plenum Press.

Gerver, D., Longley, P., Long, J. and Lambert, S. (1984) Selecting trainee conference interpreters: a preliminary report. In Journal of Occupational Psychology, 57 (1), 17-31.

Gerver, D., Longley, P., Long, J. and Lambert, S. (1989) Selection tests for trainee conference interpreters. In Meta, 34 (4), 72435.

Gile, D. (1985) Le modèl d'efforts et l'équilibre d'interprétation en interprétation simultanée. In Meta, 30 (1), 44-48.

Gile, D. (1989) La communication linguistique en reunion multilingue, les difficultées de la transmission informationelle en interprétation simultanée. Unpublished Ph.D. thesis. Paris: Université Paris III.

Gile, D. (1991a) The processing capacity issue in conference interpretation. In Babel, 37 (1), 15-27.

Gile, D. (1991b) Prise de notes et attention en debut d'apprentissage de l'interprétation consécutive - une experience - démonstration de sensibilisation. In Meta, 36 (2/3), 432-41. 
Goldman-Eisler, F. (1967) Sequential temporal patterns and cognitive process in speech. In Language and Speech, 10, 122132.

Goldman-Eisler, F. (1972) Segmentation of input in simultaneous interpretation. In Journal of Psycholinguisic Research, 1,127140.

Green, A., Schweda-Nicholson, N., Vaid, J., White, N., and Steiner, R. (1990) Hemispheric involvement in shadowing vs. interpretation: a time-sharing study of simultaneous interpreters with matched bilingual and monolingual controls. In Brain and Language, 39, 107-133.

Hamers, J. F. and Blanc, M. H. A. (1989) Bilinguality and Bilingualism. Cambridge: Cambridge University Press.

Harris, B. and Sherwood, B. (1978) Translating as an innate skill. In D. Gerver and H. W. Sinaiko (eds.) Language. Interpretation and Communication. New York: Plenum Press.

Howells, G. W. (n.d.) Personality characteristics of simultaneous interpreters. Unpublished research report.

Hromosova, A. A. (1972) A study of memory in interpreting. In Acta Universitatis, 17 novembris, Pragensis III.

Hamers, J. F. and Blanc, M. H. A. (1989) Bilinquality and Bilingualism. Cambridge: Cambridge University Press.

Hu, G. (1991) A "credit" model assessing interpretation effects. In Babel, 37 (3), 152-167.

Isham, W. P. and Lane, H. (1993) Simultaneous interpretation and the recall of source-language sentences. In Language and Cognitive Processes, 8 (3), 241-64.

Jackendoff, R. S. (1972) Semantic Interpretation in Generative Grammar. Cambridge: MIT Press. 
Kalina, S. (1992) Discourse processing and interpreting strategies. In C. Dollerup and A. Loddegaard (eds.) Teaching Translation and Interpretation. Amsterdam: J. Benjamins.

Kintsch, W. and vanDijk, T. A. (1978) Toward a model of text comprehension and production. In Psychological Review, 85 (5), 363-394.

Kolers, P. (1973) Bilingualism and information processing. In Scientific American, 220, 78-86.

Kuhn, T. (1970) The Structure of Scientific Revolution. Chicago: University of Chicago Press.

Kurz, I. (1986a) Dolmetschen im alten Rom. In Babel, 4 (32), 215220.

Kurz, I. (1986b) Das Dolmetscher-Relief aus dem Grab des Haremhab in Memphis. Ein Beitrag zur Geschichte des Dolmetschens im alten Aegypten In Babel, 4 (32), 73-77.

Kurz, I. (1992) 'Shadowing' exercises in interpreter training. In C. Dollerup and A. Loddegaard (eds.) Teaching Translation and Interpretation. Amsterdam: J. Benjamins.

Lambert, S. (1978) Psychological approaches to bilingualism. In D. Gerver and H. W. Sinaiko (eds.) Language. Interpretation and Communication. New York: Plenum Press.

Lambert, S. (1983) Recall and recognition among conference interpreters. Unpublished Ph.D. dissertation. Stirling,Scotland: University of Stirling.

Lambert, S. (1988) A human information processing and cognitive model to the training of simultaneous interpreters. In $D$. $L$. Hammond (ed.) Languages at Crossroads: Proceedings of the 29th Annual Conference of the American Translator Association. Medford, NJ: Learned Information Inc.

Lambert, S. (1989) La formation d'interprètes : la méthode cognitive. In Meta, 34 (4), 736-44. 
Lawson, E. A. (1967) Attention and simultaneous interpretation. InLanguage and Speech, 10, 29-35.

Le Ny, J. F. (1978) Psychosemantics and simultaneous interpretation. In D. Gerver and H. W. Sinaiko (eds.) Language. Interpretation and Communication. New York: Plenum Press.

Lederer, M. (1981) La Traduction Simultanée. Paris: Lettres Modernes.

Lederer, M. (1985) L'interprétation, manifestation élementaire de la traduction. In Meta, 30 (1), 25-30.

Levelt, W. J. M. (1989) Speaking. From Intension to Articulation. Cambridge: MIT Press.

Lieberman, P. (1963) Some effects of semantic and grammatical context on the production and perception of speech. In Language and Speech, 6, 172-187.

Lyons, J. (1981) Lanquage. Meaning and Context. London: Fontana.

Maarten Schraagen, J. (1993) How experts solve a novel problem in experimental design. In Cognitive Science, 17, 285-309.

Mackintosh, J. (1985) The Kintsch and VanDijk model of discourse comprehension and production applied to the interpretation process. In Meta, 30 (1), 37-43.

Massaro, D.W. (1978) An information processing model of understanding speech. In D. Gerver and H. W. Sinaiko (eds.) Language. Interpretation and Communication. New York: Plenum Press.

McClelland, J. L. and Rumelhart, D. E. (1981) An interactive activation model of context effects in letter perception: part 1. An account of basic findings. In Psychological Review, 88, 375407. 
McCormack, P. D. (1977) Bilingual linguistic memory: the independence-interdependence issue revisited. In P. A. Hornby (ed.) Bilingualism: Psychological. Social and Educational Implications. New York: Academic Press.

Miller, G. A., Galanter, E. and Pribram, K. H. (1960) Plans and the Structure of Behavior. New York: Holt, Rinehart, and Winston.

Miller, G. A. (1964) Adjusting to overloads of information. In Research on Public Assistance for Nervous and Mental Disease, 42, 87-100.

Morris, N. and Jones, D. M. (1990) Memory updating in working memory. In British Journal of Psychology, 81, 111-121.

Moser, B. (1978) Simultaneous interpretion: a hypothetical model and its practical application. In D. Gerver and H. W. Sinaiko (eds.) Language. Interpretation and Communication. New York: Plenum Press.

Neisser, U. (1966) Cognitive Psychology. New York: AppletonCentury-Croft.

Nida, E. A. (1964) Ioward a Science of Translating. Leiden: E. J. Brill.

Nida, E. A. (1966) Principles of translation as exemplified by Bible translating. In R. A. Brower (ed.) On Translation. Oxford: Oxford University Press.

Nida, E. A. and Taber, C. (1974) The Theory and Practice of Translation. Leiden: E. J. Brill.

Nirenburg, S. (ed.) (1987) Machine Translation: Theoretical and Methodological Issues. Cambridge: Cambridge University Press.

Oleron, P. and Nanpon, H. (1965) Recherches sur la traduction simultanée. In Journal de Psychologie Normale et Pathologique, 6, 73-94.

Osherson, D.N. and Lasnik, H. (eds.) (1990) An Invitation to Cognitive Science (vol. 1). Cambridge: MIT Press. 
Paivio, A. and Lambert, W. E. (1981) Dual coding and bilingual memory. In Journal of Verbal Learning and Verbal Behavior, 20, 532-39.

Paneth, E. (1957) An investigation into conference interpreting. Unpublished Master's thesis. London: London University.

Paradis, M. (1985) On the representation of two languages in one brain. In Language Sciences, 7 (2), 1-36.

Paradis, M., Goldblum M. C., and Abidi, R. (1989) Alternate antagonism with paradoxical translation behaviour in two bilinguals. In Brain andLanguage, 15, 55-69.

Pattnaik, K. and Mohanty, A. K. (1984) Relationships between metalinguistic and cognitive development of bilingual and unilingual tribal children. In Psycho-Lingua, 14, 63-70.

Pinhas, R. (1972) Les retombés scientifiques des opérations "Apollo" sur l'interpretation simultanee. In La Linguistique, 8, 143-147.

Pintner, I. (1969) Der Einfluss der Uebung und Konzentration auf simultanes Sprechen und Hoeren. Unpublished Ph.D. thesis. Vienna: University of Vienna.

Poechhacker, F. (1992) The role of theory in simultaneous interpretation. In C. Dollerup and A. Loddegaard (eds.) Teaching Translation and Interpretation. Amsterdam: J. Benjamins.

Potter, M. C., So, K., Von Eckardt, B. and Feldman, L. B. (1984) Lexical and conceptual representation in beginning and proficient bilinguals. In Journal of Verbal Learning and Verbal Behavior, 23, 23-28.

Renfer, C. (1992) The two-tiers system. In C. Dollerup and A. Loddegaard (eds.) Teaching Translation and Interpretation. Amsterdam: J. Benjamins.

Rozan, J. F. (1956) La prise de notes en interprétation consécutive. Geneva: Georg. 
Rumelhart,D. E. and McClelland, J. L. (1982) An interactive activation model of context effects in letter perception: part 2 . The contextual enhancement effect and some tests and extensions of the model. In Psychological Review, 89, 60-94.

Schwartz, B. and Reisberg, D. (1991) Learning and Memory. New York: W. W. Norton.

Schwartz, J. and Jaffe, J. (1968) Markovian prediction of sequential temporal patterns in spontaneous language. In Language and Speech, 11, 27-30.

Schweda-Nicholson, N. (1992) Linguistic theory and simultaneous interpretation: semantic and pragmatic considerations. In Babel, 38 (2), 90-100.

Seleskovitch, D. (1968) L'Interprète dans les conférences. Paris: Lettres modernes.

Seleskovitch, D. (1975) Langages. Langues et memoire. Paris/ Bruxelles: Didier Erudition.

Seleskovitch, D. (1976) Traduire: de l'experience aux concepts. In Etudes de Linguistique Appliquee, 24, 64-91.

Seleskovitch, D. (1978) Interpretation: A psycholinguistical approach translation. In R. W. Brislin (ed.) Iranslation: Application and Research. New York: Gardner.

Seleskovitch, D. and Lederer, M. (1986) Interprèter pour Traduire. Paris: Didier.

Sharples, M., Hogg, D., Hutchison, C., Torrance, S. and Young, D. (1989) Computers and Thought: A Practical Introduction to Artificial Intelligence. Cambridge: MIT Press.

Smyth, M. M., Morris, P. E., Levy, P., and Ellis, A. W. (1987) Cognition in Action. Hove: L. Erlbaum Associates. 
Stenzl, C. (1983) Simultaneous interpretation : groundwork towards a comprehensive model. Unpublished MA dissertation. London: Birkbeck College, University of London.

Sternberg, R. J. (1985) Human Abilities and Information Processing. New Yor: W. H. Freeman.

Stevenson, R. J. (1993) Language. Thought and Representation. Chichester: Wiley.

Stillings, N. A. (ed.) (1987) Cognitive Sience: An Introduction. Cambridge: MIT Press.

Treisman, A. (1964) Monitoring and storage of irrelevant messages in selective attention. In Journal of Verbal Learning and Verbal Behavior, 6, 449-559.

Treisman, A. (1965) The effects of redundancy and familiarity on translating and repeating back a foreign and a native language. In British Journal of Psychology, 56, 369-379.

Vaid, J. and Lambert, W. (1979) Differential cerebral involvement in the cognitive functioning of bilinguals. In Brain and Language, 8 , 92-110.

Van der Linden, M., Coyette, F., and Seron, X. (1992) Selective impairment of the "central executive" component of working memory: a single case study. In Cognitive Neuropsychology, 9 (4), 301-27.

Van Hoof, H. (1962) Théorie et pratique de la traduction. Munich: Max Hueber.

Viaggio, S. (1988) Teaching interpretation to beginners: or, how not to scare them to death. In D. L. Hammond (ed.) Languages at Crossroads. Proceedings of the 29th Annual Conference of the American Translators Association. Medford, NJ: Learned Information Inc.

Welford, A. I. (1968) The Fundamentals of Skill. London: Methuen. 
Wilks, Y. (1978) Four generations of machine translation research and prospects for the future. In D. Gerver and H.W. Sinaiko (eds.) Lanquage. Interpretation and Communication. New York: Plenum Press.

Willet, R. 1974. Die Ausbildung zum Konferenzdolmetscher. In V. Knapp (ed.) Uebersetzer und Dolmetscher. Heidelberg: Quelle und Meyer. 